\title{
Spatial and Nonspatial Influences on the TQ-ST Segment Deflection of Ischemia
}

\author{
THEORETICAL AND EXPERIMENTAL ANALYSIS IN THE PIG
}

Roger P. Holland and HAROLD BROOKS with the technical assistance of BARBARA LidL

From the Hecht Experimental Hemodynamics Laboratory, Department of Medicine-Cardiology, The University of Chicago Pritzker School of Medicine, Chicago, Illinois 60637

\begin{abstract}
A B S T R A C T Spatial and nonspatial aspects of TQ-ST segment mapping were studied with the solid angle theorem and randomly coded data from 15,000 electrograms of 160 anterior descending artery occlusions each of 100-s duration performed in 18 pigs. Factors analyzed included electrode location, ischemic area and shape, wall thickness, and increases in plasma potassium $\left(\mathrm{K}^{+}\right)$. Change from control in the TQ-ST recorded at $60 \mathrm{~s}$ ( $\Delta \mathrm{TQ}-\mathrm{ST}$ ) was measured at 22 ischemic (IS) and nonischemic (NIS) epicardial sites overlying right $(\mathrm{RV})$ and left (LV) ventricles. In IS regions, $\Delta \mathrm{TQ}-\mathrm{ST}$ decreased according to $L V>$ septum $>R V$ and $L V$ base $>\mathrm{LV}$ apex. In NIS regions, LV sites had negative (Neg) $\Delta$ TQ-ST which increased as LV IS border was approached. However, RV NIS had positive (Pos) $\Delta$ TQ-ST which again increased as RV IS border was approached. With large artery occlusion IS area increased $123 \pm 18 \%, \Delta$ TQ-ST at IS sites decreased $(-38.1 \pm 3.6 \%)$, and sum of $\Delta \mathrm{TQ}-\mathrm{ST}$ at IS sites increased by only $67.3 \pm 10.3 \%$. In RV NIS Pos $\Delta$ TQST became Neg. With increased $\mathrm{K}^{+}, \Delta \mathrm{TQ}-\mathrm{ST}$ decreased proportionately to $\log \mathrm{K}^{+}(r=0.97 \pm 0.01)$ at IS and NIS sites on the epicardium and precordium. TQ-ST at $60 \mathrm{~s}$ was obliterated when $\mathrm{K}^{+}=8.7 \pm 0.2 \mathrm{mM}$. All findings were significant $(P<0.005)$ and agreed with the solid angle theorem. Thus, a transmembrane potential difference and current flow at the IS boundary alone are responsible for the TQ-ST. Nonspatial factors affect the magnitude of transmembrane potential difference, while spatial factors alter the position of the boundary to the electrode site.
\end{abstract}

Presented, in part, at the 49th Annual Scientific Session of the American Heart Association, Miami, Fla., November 1976.

Received for publication 16 June 1976 and in revised form 3 January 1977.

\section{INTRODUCTION}

"No other part of the electrocardiogram is subject to so many theories, interpretations, and even more misinterpretations as the ST interval," Shaefer and Haas (1). "The nature of these electrocardiographic changes is in no way mysterious," Wilson et al. (2).

Techniques currently used to assess ischemic/ infarcted myocardium include hemodynamic monitoring, creatine phosphokinase (CPK) ${ }^{1}$ curve analysis, myocardial radionuclide imaging, and precordial TQST segment mapping. The latter has enjoyed considerable popularity due primarily to its low cost, noninvasive approach, and simply applied rules of interpretation. Controversy has arisen recently, however, for despite all the time, effort, and resources invested in TQ-ST segment mapping studies, basic appreciation of the complex manner by which the TQ-ST segment deflection relates to the underlying ischemic region has been lacking. Inevitably, confusion and disagreement over the specificity and quantitative value of this electrocardiographic measure of

\footnotetext{
${ }^{1}$ Abbreviations used in this paper: CPK, creatine phosphokinase; ECG, electrocardiogram; $\left[\mathrm{K}^{+}\right]_{0}$, plasma potassium; LAD, left anterior descending coronary artery; LV, left ventricle; $\mathrm{RV}$, right ventricle; $\overline{\mathrm{SA}}$, average solid angle; $\Sigma \mathrm{SA}$; summed solid angle; $\operatorname{SUM}(+)$, $\operatorname{SUM}(-)$, sum of all positive and negative TQ-ST deflections, respectively; TQ-ST preocclusion TQ-ST segment deflection; $\triangle T Q-S T$, individual TQ-ST segment deflection changes; $\overline{\Delta T Q-S T}$, average change in the TQ-ST segment; $\Sigma$ TQ-ST, sum of individual TQ-ST segment deflection changes from the ischemic region; $V_{m_{1}}$, transmembrane potential of the ischemic region; $V_{m_{N}}$, transmembrane potential of the normal region; $\Delta V_{m}$, transmembrane potential difference; $\epsilon$, TQ-ST segment deflection; $\Omega$, solid angle subtended at recording site by the ischemic boundary.
} 


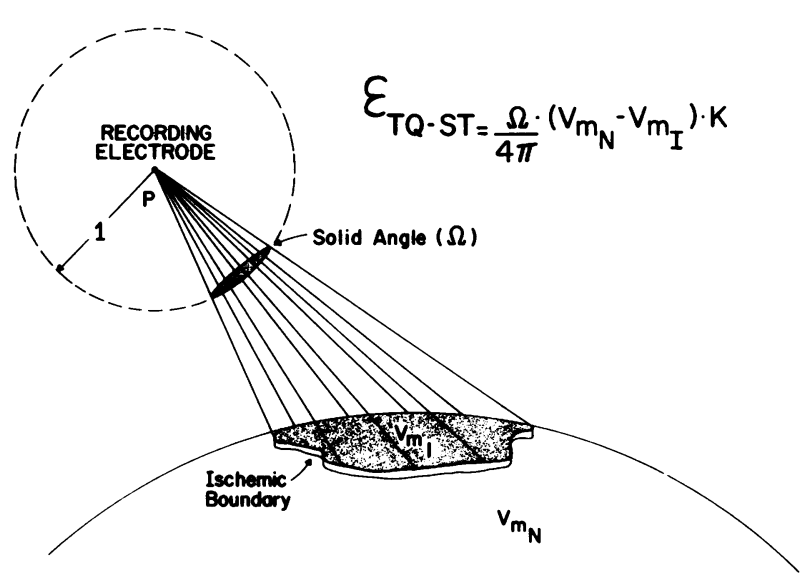

FIGURE 1 Mathematic and pictorial characterization of the solid angle theory. The solid angle $\Omega$ is defined as the area of spherical surface cut off a unit sphere (inscribed about the recording electrode) by a cone formed by drawing lines from the recording electrode to every point along the ischemic boundary. The ischemic boundary is a source of current flow established by differences in the transmembrane potentials of the normal $\left(V_{m_{N}}\right)$ and ischemic $\left(V_{m_{1}}\right)$ cells during diastole and systole. The TQ-ST segment voltage $\epsilon$ recorded at the electrode is given by the above equation. $K$ is a term correcting for differences in intra- and extracellular conductivity and the occupancy of much of the heart muscle by interstitial tissue and space. See text for additional discussion. Adapted from Holland and Arnsdorf (19).

myocardial injury was to be expected (3-11). Recognizing the current renewed interest in this area and the profound clinical value of being able to quantify ischemic damage, we have in this study examined in a theoretical and experimental manner some basic spatial and nonspatial factors influencing the magnitude and polarity of TQ-ST deflection during myocardial ischemia.

\section{METHODS}

\section{Nomenclature}

Many studies have shown that the injury deflection, conventionally referred to as the "ST segment deflection," has a diastolic as well as a systolic component. For this reason we have here, as in other studies $(12,13)$, referred to this deflection as the "TQ-ST segment deflection." So-called "ST segment elevation," then, is actually the summation of TQ depression and ST elevation (14-17). Due to capacitive coupling of most electrocardiogram (ECG) recording apparatus, the fact that the TQ segment is often not at zero potential (isoelectric) may not be obvious. The relative contribution of the diastolic (TQ segment) and systolic (ST segment) components to the total TQ-ST segment deflection has not yet been clearly established (14-17).

\section{Mathematical formulations from the solid angle theorem}

The solid angle theorem was used in this study to mathematically describe the behavior of the TQ-ST segment dur- ing ischemia. According to the theorem (Fig. 1) the magnitude and polarity of the TQ-ST segment deflection $(\epsilon)$ recorded at an electrode site $P$ is equal to the product of three parameters. $\Omega$ is the solid angle subtended at $P$ by the ischemic boundary; $V_{m_{N}}$ and $V_{m_{d}}$ denote the transmembrane potentials of the normal and ischemic region during either diastole (TQ segment) or systole (ST segment); and $K$ is a term correcting for differences in intraand extracellular conductivity and the occupancy of much of the heart muscle by interstitial tissue and space $(13,18-$ 21 ). Since the solid angle depends only upon the position of the recording electrode and the geometry of the ischemic boundary, it reflects spatial influences on the magnitude of the TQ-ST deflection. The difference in transmembrane potential between the two regions does not, however, depend upon geometry and thus reflects nonspatial influences on the TQ-ST deflection.

Spatial influences were studied with a three-dimensional spherical model of the heart containing a well-defined ischemic region (12). Calculations of solid angle values in this model then permitted analysis of various spatial relationships existing between the recording electrode and the geometry of the ischemic region. These spatial relationships were simulated in the model with the help of a spherical coordinate system (see Appendix), FORTRAN IV programming language, and a Sigma $\mathrm{V}$ digital computer (Sigma Instruments, Inc., Braintree, Mass.). The ischemic heart model used in this study, unless otherwise stated, had outer and inner wall radii of 3.0 and $2.0 \mathrm{~cm}$, respectively. The shape of the ischemic region was assumed to be transmural.

\section{Experiments in the intact heart}

Animal model. Experiments were performed in 18 openchest, domestic, neutered male pigs weighing from 35 to 60 $\mathrm{kg}$. The pig was chosen because of similarities between the gross coronary artery architecture (22) and collateral circulation (23) of this animal and man. In addition, the high degree of reproducibility of the coronary architecture (22) among individual animals, as well as the less extensive distribution of collateral vessels in the pig ventricle as compared to the dog ventricle, insures that occlusion of a certain length of a coronary artery (24) results in a visually (cyanotic discoloration) and electrically identifiable area of ischemic damage. The degree of reproducibility is documented in the Results section of this paper.

Surgery. After induction of anesthesia with a small intravenous injection of thiopental, the animals were anesthetized with an intravenous infusion of a warmed solution of alpha-chloralose $(60 \mathrm{mg} / \mathrm{kg})$. During the study, supplementary doses of chloralose were given to maintain a relatively uniform state of anesthesia. The hemodynamic actions of chloralose are minimal and transient in duration (25). Respiration was maintained by a volume respirator (Harvard Apparatus Co., Inc., Millis, Mass.), regulated to maintain an arterial $\mathrm{pH}$ of $7.45 \pm 0.05$ throughout the experiment. The pump was connected to a tracheostomy tube and supplemental oxygen was administered to maintain arterial oxygen saturation at $95 \%$. The heart was exposed by a midsternal thoracotomy, a pericardiotomy was performed, and a pericardial cradle was created to support the exposed heart.

Hemodynamic measurements. Heart rate was kept constant at 125 beats/min. This was accomplished by placing a bipolar electrode in the wall of the right auricular appendage and stimulating with a Grass stimulator (Grass Instrument Co., Quincy, Mass.) and an optical isolation unit. Stimulus duration was 5 ms. Animals whose resting 

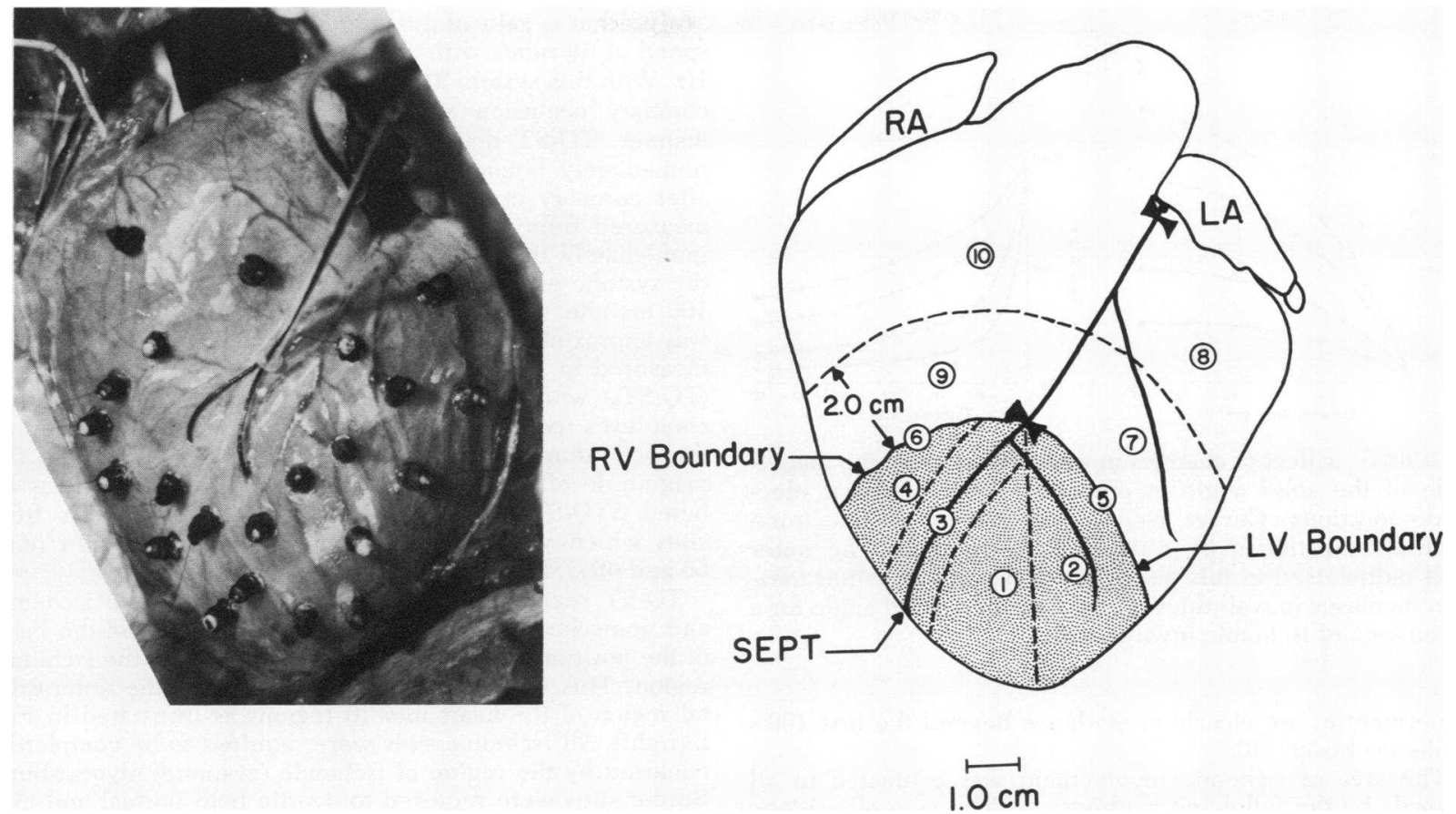

FIGURE 2 Left. Location of epicardial electrodes on the anterior surface of the pig heart. Right. Anatomic classification of electrode sites. Ischemic sites $(1,2,3,4)$ lie completely inside ischemic (cyanotic) region (shaded area). Border sites $(5,6)$ overlay both normal and cyanotic tissue. Septal (SEPT) sites (3) were within $0.5 \mathrm{~cm}$ (dashed parallel lines) of the main trunk of the LAD artery and separated the RV and LV. LV ischemic sites were further subdivided into those overlying apical (1) and more basally (2) located portions of the ischemic region by a line (vertical dashed line) drawn from the site of the small artery occlusion to the apex of the heart. Nonischemic sites $(7,8,9,10)$ were labeled as either "near" $(7,9)$ for those within $2.0 \mathrm{~cm}$ of the boundary (curved dashed line) or "distant" $(8,10)$ for those located further away. The position of the large artery occlusion is also illustrated. The length of LAD occluded (LAD) was measured in millimeters from the site of occlusion to the apical termination of the LAD (SEPT arrow).

heart rate exceeded 125 beats/min were excluded from this study. Pressure determinations were made through 6inch Teflon 16T gauge catheters connected directly to Statham P23 Db pressure transducers (Statham Instruments Div., Gould, Inc., Oxnard, Calif.) without intervening tubing. Systemic pressure was obtained by placing the catheter in the left carotid artery and left ventricular pressure by placing it in the left ventricular cavity at the apex. The left ventricular pressure was differentiated electronically to obtain the time derivative of left ventricular pressure (LV dP/dt). Left ventricular end-diastolic pressure measurements were made from high-gain tracings via an additional amplifier (1 mm Hg/division).

In those animals in which the pattern of TQ-ST segment deflections was studied at different levels of plasma potassium $\left(\left[\mathrm{K}^{+}\right]_{0}\right),\left[\mathrm{K}^{+}\right]_{0}$ was increased from control values by a slow intravenous infusion of $\mathrm{KCl}$ with an infusion pump. $\left[\mathrm{K}^{+}\right]_{0}$ levels were obtained from heparinized carotid arterial samples taken immediately after the beginning of each coronary occlusion and were measured with a flame photometer (Instrumentation Laboratory, Inc., Lexington, Mass.).

Ischemic area. The anterior left ventricular free wall supplied by branches of the left anterior descending (LAD) artery was selected for study. Reproducible areas of ischemic involvement in all animals were obtained by placing a silk ligature $(\mathrm{OO})$ around the LAD artery at a point approximately one-third to one-half the distance from the apical termination of the LAD to its origin from the left main coronary artery. Reversible occlusion was obtained with a polyethylene collar. In those experiments in which large and small areas of ischemic involvement were compared, the larger area was produced by occluding the anterior descending artery at a point approximately $1.0 \mathrm{~cm}$ from its origin with the left main coronary artery. This insured that the large area completely enclosed the small area. Occlusions were limited to 100-s duration. Recent studies have demonstrated that although ischemic TQ-ST segment deflections return towards normal after release of a brief occlusion(5-10 min), return of contractile activity is delayed and may exhibit a permanent deficit (26-28). Thus, to insure complete functional (biochemical, electrical, mechanical, etc.) recovery of the ischemic segment, it would appear necessary to limit the occlusions to very short periods of time, instead of the $15-20$-min occlusions of most studies $(5,29)$. Although the TQ-ST segment deflection has not obtained a steady-state value by this time (100 s), there is no indication from earlier studies that steady-state values are reached at any time within the lst $h$ after occlusion. Finally, the incidence of conduction abnormalities (QRS complex, loss of the $S$ wave, ectopic beats, etc.) which may either obliterate, mimic, or alter the TQ-ST segment deflection characteristic of ischemia increases with the duration of the occlusion $(5,30)$. In the pig, such 


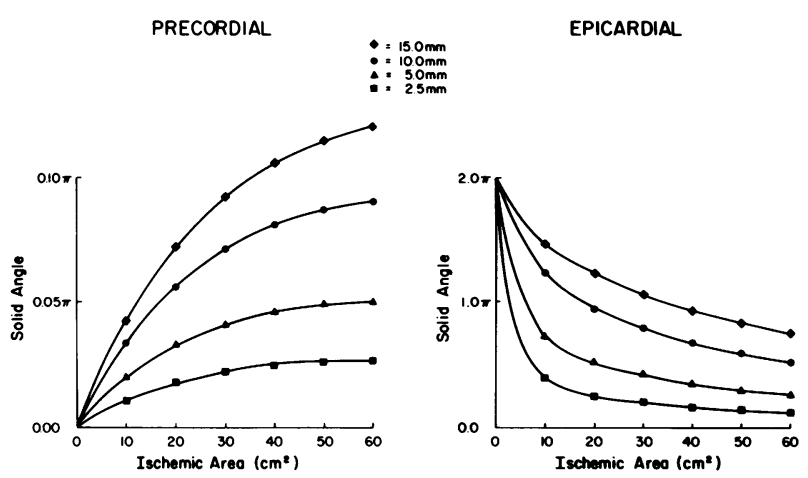

FIGURE 3 Effect of changes in wall thickness on the magnitude of the solid angle at precordial and epicardial electrode locations. Curves were derived with the electrode centrally positioned over the ischemic region. The outer wall radius used in this analysis was $3.5 \mathrm{~cm}$. At either location increases in wall thickness increase the solid angle for a given area of ischemic involvement.

abnormalities are clearly in evidence beyond the first $100 \mathrm{~s}$ of the occlusion (30).

The area of ischemic involvement was estimated in all animals by the following methods: ( $a$ ) The area of cyanotic discoloration after the first occlusion was drawn to scale on a previously sketched anterolateral view of the porcine heart which included the distribution of the LAD artery and its primary branches (31); (b) At postmortem, the length of LAD artery occluded was perfused with methylene blue dye and the stained epicardial surface area along with various anatomic arterial landmarks was measured with a pair of calipers. The two areas (cyanotic and stained) were then calculated by planimetry and the caliper values; $(c)$ The mass of stained tissue (ischemic weight) after the above dye infusion was then cut out and weighed (24). Agreement in the two methods of estimating ischemic area is documented in the Results section of this article.

Electrical measurements. Epicardial electrical potentials were recorded from the heart's surface with 22 atraumatic, firmly attaching electrodes designed in this laboratory. The electrodes are a modification of the original design (32) and are constructed from polished brass screws having a surface area of $14 \mathrm{~mm}^{2}$ (radius $=2.2 \mathrm{~mm}$ ). The electrodes were spaced equidistant from one another over the anterior surface of the left and right ventricles in the distribution of the LAD artery (Fig. 2, left).

The need for near-simultaneous recordings of the electrograms from 22 sites required that an automated rapid electromechanical switching circuit be designed (32). Basically the system consists of a pulse generator and two stepping relays. Upon receiving a pulse the stepping relay is advanced and connects a particular electrode site to the ECG amplifier for a period of $0.8 \mathrm{~s}$. The heart rate of 125 beats $/ \mathrm{min}$ used in this study permits approximately $1 \frac{1}{2}$ heart beats to be recorded at each site. By using a pair of calibrated bioelectric amplifiers (No. 8811A, Hewlett-Packard Co., Palo Alto, Calif.) with a frequency response of DC to $10 \mathrm{kHz}$, all 22 electrode sites could be sampled within the space of $10 \mathrm{~s}$. The signals were simultaneously recorded on FM magnetic tape (73/4 ips) and displayed on a high speed chart recorder along with the hemodynamic signals. The FM tape recorder had a frequency response of $D C$ to $2.5 \mathrm{kHz}$, a signal-to-noise ratio of $44 \mathrm{~dB}$, total harmonic distortion of $2 \%$, and flutter of $0.4 \%$. The resulting signals were then analyzed at a gain of $1.0 \mathrm{mV} / \mathrm{div}$ and an equivalent paper speed of $50 \mathrm{~mm} / \mathrm{s}$ with a frequency response of DC to 400 Hz. With this system TQ-ST segment deflections after acute coronary occlusion were characterized in the following manner. TQ-ST deflections were measured from all sites immediately before occlusion (control) and at exactly $60 \mathrm{~s}$ after coronary occlusion. The total TQ-ST deflection was measured from that portion of the TQ segment occurring immediately before the inscription of the QRS complex to the systolic endpoint, a point on the ST segment occurring $100 \mathrm{~ms}$ after onset of the QRS complex (33). Track width was approximately $1 / 5$ of a division and TQ-ST values were measured to $1 / 10$ of a division $(0.1 \mathrm{mV})$. The control values (TQ-ST ${ }_{0}$ ) were obtained from the mean of multiple (2-4) complexes recorded during the $30 \mathrm{~s}$ immediately preceding the occlusion. The difference between this value and the magnitude of the deflection at $60 \mathrm{~s}$ after occlusion was labeled $\triangle T Q-S T$. To obtain values for TQ-ST at $60 \mathrm{~s}$ from sites which were sampled at times other than $60 \mathrm{~s}$ (e.g., 56 and $66 \mathrm{~s}$ ), linear interpolation was employed.

TQ-ST segment deflection changes at multiple ischemic and nonischemic sites were categorized solely on the basis of the position of the various recording sites to the ischemic region. This was accomplished by dividing the anteroseptal region of the heart into 10 regions as illustrated in Fig. 2 (right). All ischemic sites were required to be completely enclosed by the region of ischemic (cyanotic) myocardium. Border sites were required to overlie both normal and cyanotic tissue and thus the width of the border was defined by the electrode diameter $(4.4 \mathrm{~mm})$. Septal ischemic sites were within $0.5 \mathrm{~cm}$ of the main trunk of the LAD. Left ventricular ischemic sites were further subdivided into sites lying in thin, apical portions of the ischemic region and those in the thicker-walled areas nearer the base of the heart. This was again accomplished in an unbiased fashion by drawing an imaginary line from the site of the occlusion to the apex of heart (see Fig. 2). All electrode locations were placed in 1 of the 10 categories before measurement of their electrogram tracings.

Data analysis. To avoid any prejudicial measurement of the TQ-ST segment deflections, all electrogram tracings were randomly coded and evaluated without knowledge as to electrode locations. As a result of the requirement for multiple measurements of the TQ-ST segment deflection an average of 100 determinations were made during each occlusion and thus in the course of this study in excess of 15,000 electrogram tracings were evaluated. Statistical analysis was confined to paired and unpaired $t$-tests and linear regression analysis (34) carried out with the help of a Wang 700 desk calculator (Wang Laboratories, Inc., Lowell, Mass.).

\section{RESULTS}

\section{Theoretical analysis}

In Fig. 3 the effect of different wall thicknesses and areas of ischemic involvement on the solid angle subtended at precordial and epicardial locations is illustrated. Although increases in ischemic size increase the magnitude of the solid angle at precordial locations, and decrease it at epicardial sites (12), at either location increases in wall thickness increase the solid angle. This finding immediately suggested that for equivalent areas of ischemic involvement, TQ-ST deflections recorded at thick-walled portions 
PRECORDIAL

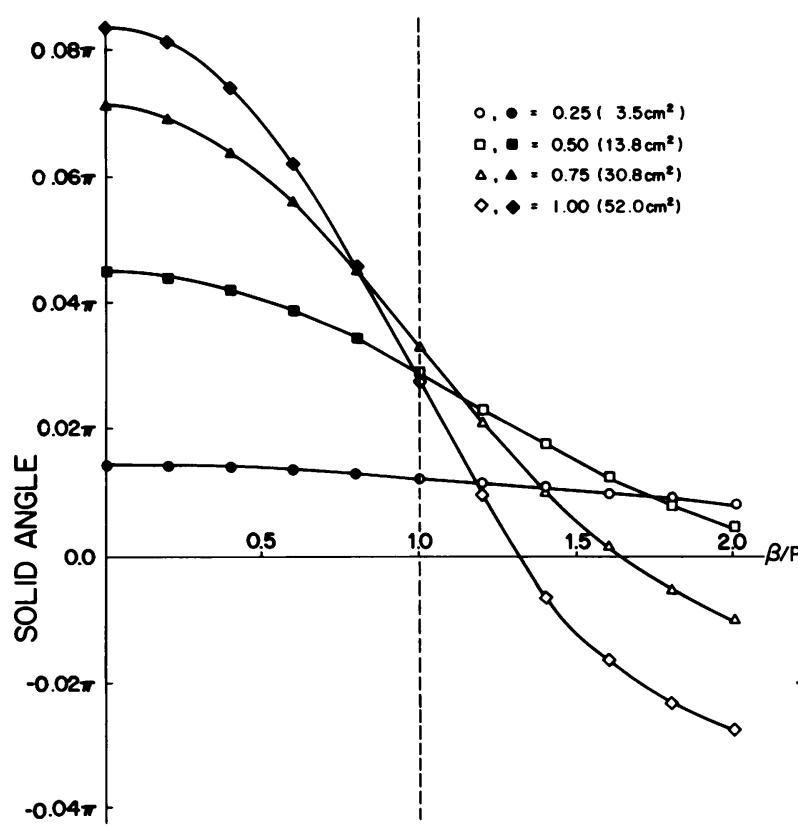

EPICARDIAL

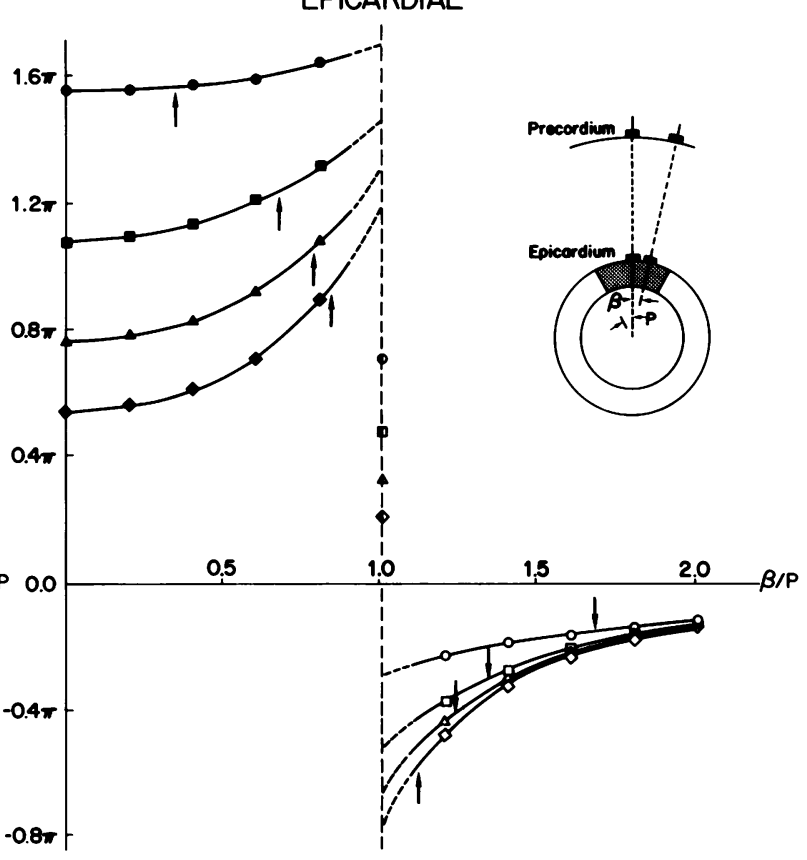

FIGURE 4 Influence of electrode position with respect to the ischemic boundary (dashed vertical line) on the polarity and magnitude of the solid angle computed at precordial and epicardial locations for different ischemic areas. Electrodes overlying ischemic regions (solid symbols) have positive solid angle values at either location. On the precordium, negative solid angle values occur at sites distant from the boundary while at the epicardium negative values are recorded from all nonischemic regions (clear symbols). Dashed lines indicate uncertainty of solid angle values at the epicardium and in the vicinity of the ischemic boundary. Arrows identify solid angle values at epicardial sites within $0.5 \mathrm{~cm}$ of ischemic boundary. Note that at the epicardium the negative solid angle values in the nonischemic region increase in magnitude with increases in ischemic area despite a reduction in the magnitude of the positive solid angle values of the ischemic region.

(base) of the ischemic left ventricle should exceed those recorded at the thinner-walled apex. Similarly, the TQ-ST deflection at left ventricular sites should exceed the magnitude of the deflections from right ventricular ischemic sites.

The solid angle values calculated above were for electrodes centrally positioned over a circular area of ischemic involvement. However, in mapping studies, electrodes overlie all regions of ischemic and nonischemic tissue. The effect of moving the electrode from the center of the ischemic area $(\beta / P=0.0)$, towards the ischemic boundary $(\beta / P=1.0)$, and beyond $(\beta / \mathrm{P}>1.0)$ was computed and is shown in Fig. 4. The solid angle at precordial sites is maximal when the electrodes directly overlie the ischemic region $(\beta / P=0.0)$ and decreases at sites distant from the center $(\beta / P>0.0)$. The solid angle does not become negative until electrodes are positioned at a considerable distance from the ischemic boundary $(\beta / P \gg 1.0)$. The solid angle at epicardial sites, in comparison, increases in positivity as the boundary is approached. At the boundary a discontinuity in the curve occurs and be- yond this point, in the nonischemic regions, the epicardial solid angle is negative, rapidly decreasing in magnitude as the electrode moves further away from the ischemic boundary. Although the solid angle can assume values of either positive or negative polarity in the immediate vicinity of the boundary, on the average the solid angle values should have a positive polarity with a magnitude of approximately $40 \%$ that recorded by electrodes directly overlying the center of the ischemic region.

Having determined how the magnitude and polarity of the solid angle varies depending upon its location within the ischemic region, the summed solid angle ( $\Sigma$ SA) for different areas of ischemic involvement may be computed. $\Sigma S A$ is equal to the sum of the individual solid angles subtended at each electrode site overlying the ischemic region. In Fig. $5 \Sigma \mathrm{SA}$ and the average solid angle $\overline{\mathrm{SA}}$ were plotted as a function of ischemic area. At the precordium both $\overline{\mathrm{SA}}$ and $\Sigma S A$ increase with ischemic area. The curve relating $\overline{\mathrm{SA}}$ to ischemic area is remarkably linear over the range of areas from 5 to $50 \mathrm{~cm}^{2}$. At the epicardium the situation is 


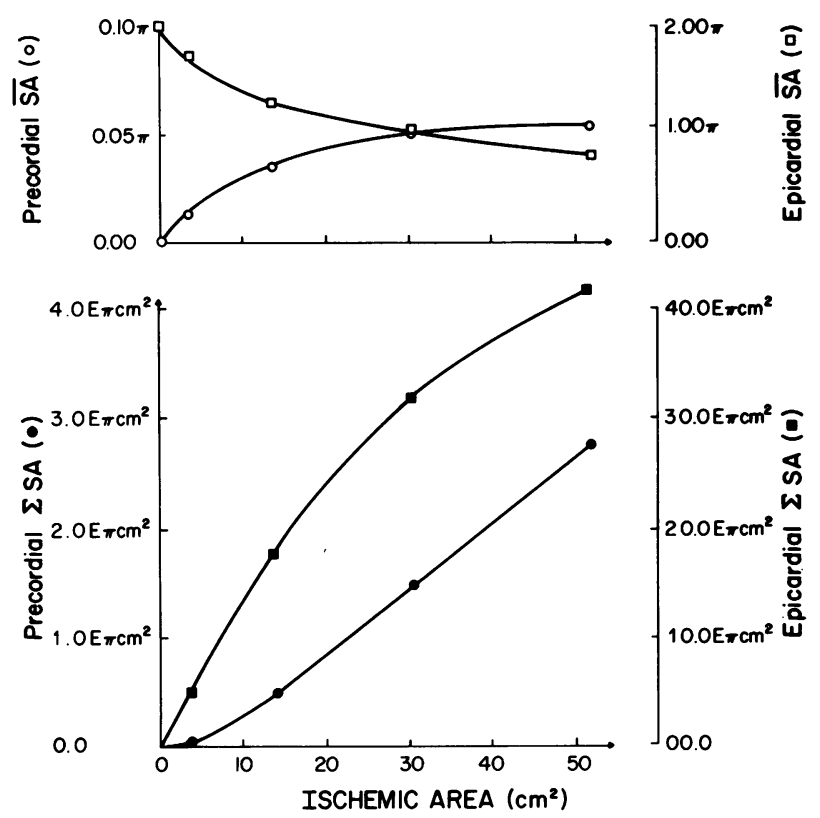

FIGURE 5 Influence of changes in ischemic area on the average $(\overline{\mathbf{S A}})$ and summed ( $\mathrm{SA}$ ) solid angle values seen by electrodes overlying the ischemic area. $\Sigma$ SA depends upon the electrode density, $E$, the area of ischemic involvement, and the $\overline{\mathrm{SA}}$ recorded at each site. The latter depends in turn upon whether the electrodes are located at the precordium or epicardium. Although $\Sigma S A$ increases with increases in ischemic area at either position, a given percentage change in ischemic area results in substantially smaller changes in $\Sigma S A$ at the epicardium. A purely linear relationship between $\Sigma S A$ and ischemic area is expected only when $\overline{\mathrm{SA}}$ is constant for all ischemic areas. This situation never exists but is approximated at precordial sites and large ischemic areas whereupon changes in ischemic area are accompanied by nearly equivalent changes in $\Sigma S A$.

different. Although $\overline{\mathrm{SA}}$ decreases with increases in ischemic area, $\Sigma S A$ increases, but in a nonlinear manner. At this location a given percentage change in ischemic area results in a substantially smaller change in $\Sigma$ SA. In the range of areas from 10 to $50 \mathrm{~cm}^{2}$ a doubling in ischemic area is met by a $22 \%$ decrease in $\overline{\mathrm{SA}}$ and only a $60 \%$ increase in $\Sigma \mathrm{SA}$ at epicardial sites; at precordial sites the change in $\Sigma$ SA $(+153 \%)$ is greater than the change in area $(+100 \%)$.

\section{Experimental verification}

Spatial influences. In Table I anatomic and hemodynamic characteristics of the experimental model and the ischemic region are tabulated. Occlusion of a specific length $(38.1 \pm 1.1 \mathrm{~mm})$ of the anterior descending coronary artery in animals of equivalent weight class resulted in the production of standard areas of ischemic involvement $\left(13.2 \pm 0.8 \mathrm{~cm}^{2}\right)$. The area of tissue becoming ischemic (cyanotic) closely approxi- mated that area normally perfused by the occluded artery (stained).

In Table II TQ-ST segment deflection changes at multiple ischemic and nonischemic sites have been tabulated from a total of 77 occlusions performed in 16 animals. As was suggested by the theoretical findings, different TQ-ST potential populations can be successfully categorized simply on the basis of spatial relationships existing between the various electrode sites and the geometry of the ischemic region. In the ischemic region TQ-ST deflections were always observed to increase in magnitude as a thickerwalled ischemic boundary was approached. Thus, the magnitudes of the individual ischemic populations decreased accordingly: left ventricle (LV) $>$ SEPT $>$ right ventricle (RV) and LV base $>L V$ apex. The relative magnitudes of the deflections at these anatomic locations exhibited even smaller variability when deflection populations were compared in each animal (Fraction column). In this case the $\mathrm{LV}$ and $\mathrm{RV}$ ischemic sites were respectively $1.47 \pm 0.06$ and $0.65 \pm 0.04$ the magnitude recorded at the septal locations, while the sites closer to the LV base were $1.25 \pm 0.06(P<0.001)$ those nearer the apex.

Although there was no significant difference in the means of the positive potential deflections recorded at the RV and LV ischemic borders, a distinction between these two populations may be noted. At the

TABLE I

Characteristics of the Experimental Model

Anatomic

Animal weight, $\mathrm{kg}$

$46.6 \pm 1.7$

Heart weight, $g$

$184.3 \pm 6.1$

Heart/animal weight, $\%$

$4.2 \pm 0.2$

Ventricle weight, $g$

$152.9 \pm 4.5$

Length of artery occluded, $\mathrm{mm}$

$38.1 \pm 1.1$

Ischemic area-cyanotic, $\mathrm{cm}^{2}$

$13.2 \pm 0.8$

Ischemic area-stained, $\mathrm{cm}^{2}$

$14.6 \pm 0.9$

Ischemic weight, $g$

$19.9 \pm 0.8$

Ischemic/ventricle weight, \%

$13.1 \pm 0.5$

Number of ischemic sites, $n$

$9.1 \pm 0.5$

Hemodynamic

MAP, $m m \mathrm{Hg}$
LVP, $m m \mathrm{Hg}$
LVEDP, $m m \mathrm{Hg}$
LV dP/dt, $m m \mathrm{Hg} / \mathrm{s}$

$102.5 \pm 5.4$

$109.1 \pm 5.2$

$6.4 \pm 0.4$

$1,649 \pm 106$

Abbreviations: MAP, mean arterial pressure; LVP, left ventricular peak systolic pressure; LVEDP, left ventricular end-diastolic pressure; $\mathrm{LV} \mathrm{dP} / \mathrm{dt}$, time derivative of left ventricular pressure.

Values shown are means \pm SEM obtained from experiments performed in 17 animals. Heart rate was kept constant at 125 beats/min. 
right ischemic border the potential deflections were always positive, while at the left negative deflections were measured in a few instances.

At electrode sites overlying nonischemic portions of the $L V$ reciprocal negative deflections were recorded, their magnitudes decreasing at locations more distant from the LV ischemic boundary. These reciprocal deflections averaged $-0.25 \pm 0.03$ (near) and -0.09 \pm 0.01 (distant) the magnitude at the ischemic septal sites.

In contrast, at nonischemic positions on the RV the polarity of the TQ-ST deflections was positive despite the fact that the sites from where they were recorded neither overlay cyanotic tissue nor were in the apparent distribution of the occluded artery. The magnitude of these deflections maintained its positivity but diminished in intensity at locations more distant from the right ventricular ischemic boundary.

In Table III the effects of small and large coronary artery occlusion on the area of ischemic involvement and the magnitude and polarity of the deflections recorded from sites overlying ischemic and nonischemic portions of the heart are tabulated. With the porcine heart model, production and subsequent measurement of a standardized area of ischemic involvement was easily accomplished. The ischemic area after large artery occlusion was approximately twice that observed after the smaller occlusion. The percentage increase in ischemic weight, however, was greater than this due presumably to the involvement of the thicker, more basally located portions of the anterior wall only during large artery occlusion.

The change in ischemic area had a predictable influence on the magnitude and polarity of the TQ-ST deflections recorded from all areas. Sites originally overlying the smaller ischemic area (LV apex) maintained their positive polarity but decreased in magnitude as the $L V$ ischemic boundary was removed to a more distant location nearer the base of the heart. New sites closer to the base of the heart, which after the small artery occlusion were in nonischemic or border regions, now registered positive deflections which exceeded in magnitude those deflections recorded at more apical portions of the ventricle. Similar though less dramatic changes were observed in the $\mathrm{RV}$ ischemic regions, for after the large artery occlusion the RV boundary extended itself upwards towards the pulmonary outflow tract but still maintained a position parallel to and a fixed distance away from the septum (Fig. 6).

Although the area of ischemic involvement more than doubled after large artery occlusion, the sum of the individual TQ-ST segment deflections from the ischemic region, $\mathrm{\Sigma TQ}-\mathrm{ST}$, increased by only 67.3 $\pm 10.3 \%$. This was predictable on the basis of the
TABLE II

TQ-ST Segment Deflections at Multiple Ischemic and Nonischemic Sites

\begin{tabular}{ccc}
\hline Magnitude & Fraction (septum) \\
\hline$m V$ &
\end{tabular}

Ischemic region

Left ventricle

Apex

Base

Difference

Septum

Right ventricle

$4.70 \pm 0.30$
$4.25 \pm 0.29$
$5.26 \pm 0.36$
$1.00 \pm 0.25^{*}$
$3.21 \pm 0.18$
$2.03 \pm 0.15$

$1.47 \pm 0.06$

$1.32 \pm 0.06$

$1.64 \pm 0.07$

$0.32 \pm 0.07 *$

1.00

$0.65 \pm 0.04$

Border region

Left ventricle

Right ventricle

$1.66 \pm 0.32$

$0.56 \pm 0.11$

$1.14 \pm 0.15$

$0.38 \pm 0.08$

Difference

$0.52 \pm 0.45$

$0.18 \pm 0.16$

Nonischemic region

Left ventricle

Near

$-0.80 \pm 0.09$

$-0.25 \pm 0.03$

Distant

$-0.28 \pm 0.05$

$-0.09 \pm 0.01$

Difference

$-0.51 \pm 0.09 *$

$-0.16 \pm 0.03$ *

Right ventricle

Near

Distant

$+0.57 \pm 0.06$

$+0.19 \pm 0.02$

Difference

$+0.19 \pm 0.05$

$+0.05 \pm 0.01$

$+0.14 \pm 0.03^{*}$

Values shown are means $\pm S E M$ obtained from experiments in 17 animals. Average number of occlusions performed in each animal was $4.5 \pm 0.5$.

* $P<0.002$; paired $t$ test.

theoretical findings and is a reasonable expectation when one considers that although the number of ischemic sites increased to the same degree as the ischemic area, the average potential deflection recorded at these sites decreased by $20 \%$. Indeed, if the thickness of the LV ischemic boundary had not increased after large artery occlusion, the average ischemic TQ-ST deflection might have experienced an even greater decrease (and $\Sigma T Q-S T$ a smaller increase) and thus might have yielded results in even closer agreement with the theoretical predictions.

In the nonischemic portions of the RV, the normal positive deflections recorded with a small area of ischemia declined in magnitude and in many instances even became negative after the large artery occlusion $(P<0.005)$. In contrast, however, the normally negative deflections recorded from the nonischemic portions of the $\mathrm{LV}$ appeared to increase in magnitude after large artery occlusion. These results suggested that the position of both right and left ischemic ventricular boundaries helped to determine both the polarity and magnitude of the deflections recorded at all sites.

This hypothesis was tested further as is illustrated 
TABLE III

Effect of Changes in Ischemic Area on the TQ-ST Segment Deflection

\begin{tabular}{|c|c|c|c|c|}
\hline & Small & Large & Difference & Change \\
\hline & & & & $\%$ \\
\hline \multicolumn{5}{|l|}{ Anatomic } \\
\hline $\mathrm{LAO}, m m$ & $39.2 \pm 1.3$ & $79.8 \pm 1.8$ & $40.6 \pm 2.5^{*}$ & $105.4 \pm 9.5^{*}$ \\
\hline IA, $\mathrm{cm}^{2}$ & $13.0 \pm 0.6$ & $28.5 \pm 1.8$ & $15.6 \pm 1.9^{*}$ & $123.3 \pm 17.9^{*}$ \\
\hline IW, $g$ & $19.6 \pm 1.0$ & $45.3 \pm 1.6$ & $25.6 \pm 1.0^{*}$ & $133.4 \pm 9.6^{*}$ \\
\hline \#IS & $8.1 \pm 0.3$ & $16.6 \pm 0.5$ & $8.5 \pm 0.5^{*}$ & $106.3 \pm 9.2^{*}$ \\
\hline \multicolumn{5}{|l|}{ Electrical } \\
\hline \multirow{2}{*}{\multicolumn{5}{|c|}{$\begin{array}{l}\text { Ischemic region } \\
\text { LV + SEPT }(\Delta T O-S T)\end{array}$}} \\
\hline \multicolumn{2}{|l|}{$\mathrm{LV}+\mathrm{SEPT}(\Delta \mathrm{TQ}-\mathrm{ST})$} & & & \\
\hline Original & $3.77 \pm 0.21$ & $2.28 \pm 0.11$ & $-1.49 \pm 0.22 *$ & $-38.5 \pm 3.6^{*}$ \\
\hline New & & $3.86 \pm 0.26 \S$ & & \\
\hline Total & $3.77 \pm 0.21$ & $3.01 \pm 0.14$ & $-0.76 \pm 0.15^{*}$ & $-19.4 \pm 3.0^{*}$ \\
\hline \multicolumn{5}{|l|}{$\mathrm{RV}(\Delta \mathrm{TQ}-\mathrm{ST})$} \\
\hline Original & $1.73 \pm 0.15$ & $1.32 \pm 0.17$ & $-0.41 \pm 0.12 \ddagger$ & $-24.9 \pm 8.2 \ddagger$ \\
\hline New & & $2.62 \pm 0.28 \S$ & & \\
\hline Total & $1.73 \pm 0.15$ & $1.95 \pm 0.20$ & $+0.23 \pm 0.23$ & $+19.1 \pm 15.7$ \\
\hline \multicolumn{5}{|l|}{$\Sigma \Delta T Q-S T$} \\
\hline Original & $28.5 \pm 2.1$ & $17.4 \pm 1.1$ & $-11.1 \pm 1.7^{*}$ & $-38.1 \pm 3.6^{*}$ \\
\hline New & & $29.8 \pm 2.9 \S$ & & \\
\hline Total & $28.5 \pm 2.1$ & $47.2 \pm 3.3$ & $+18.7 \pm 2.5^{*}$ & $67.3 \pm 10.3^{*}$ \\
\hline \multicolumn{5}{|l|}{ Nonischemic region } \\
\hline$L V+\operatorname{SEPT}(\Delta \mathrm{TQ}-\mathrm{ST})$ & $-0.59 \pm 0.12$ & $-1.14 \pm 0.50$ & $-0.55 \pm 0.35$ & $-93 \pm 59$ \\
\hline RV $(\Delta \mathrm{TQ}-\mathrm{ST})$ & $+0.44 \pm 0.08$ & $-0.25 \pm 0.12$ & $-0.69 \pm 0.15^{*}$ & $-160 \pm 26^{*}$ \\
\hline
\end{tabular}

Abbreviations: Difference, large-small; LAO, length of artery occluded; IA, area of cyanotic discoloration; IW, ischemic weight; \#IS, number of electrode sites completely overlying cyanotic region; LV + SEPT, left ventricle and septal sites; RV, right ventricle sites; $\Sigma \Delta T Q-S T$, sum of $\Delta T Q-S T$ at all ischemic sites; Original, sites overlying small ischemic area; New, additional sites becoming ischemic after large artery occlusion.

Values shown are means \pm SEM obtained from experiments performed in eight animals. The average number of small and large artery occlusions performed in each animal was 5.0 and 2.1, respectively. $\triangle T Q-S T$ at nonischemic LV + SEPT sites after large occlusions were obtained in only three animals.

${ }^{*} P<0.005$; paired $t$ test (difference and percent change).

$\ddagger P<0.02$; paired $t$ test (difference and percent change).

$\S P<0.005$; paired $t$ test (original-new).

in Fig. 6. In this experiment multiple occlusions of the small coronary artery in an animal were made and the average TQ-ST ( $\overline{\Delta T Q-S T})$ changes at all sites measured at 30,60 , and $90 \mathrm{~s}$. During every other occlusion at precisely $65 \mathrm{~s}$ after the small artery occlusion, the larger artery was then occluded. Again despite increases in the amount of ischemic damage, the deflection magnitude at sites originally overlying the smaller area of ischemia began to decline, being significantly lower $25 \mathrm{~s}$ later than if the smaller occlusion had been maintained the full $90 \mathrm{~s}$. In this example $\operatorname{SUM}(+)$ and SUM(-) refer to the sum, respectively, of all positive and negative $\triangle T Q-S T$ deflections measured from all 22 sites. With a sudden increase in ischemic area at $65 \mathrm{~s}$, sites originally overlying nonischemic regions of the $L V$ now overlay ischemic regions and began to develop positive $\Delta$ TQ-ST. Thus these sites were no longer categorized in $\operatorname{SUM}(-)$ and this parameter dramtically decreased in value. $\operatorname{SUM}(+)$ on the other hand had still not exhibited any change at $90 \mathrm{~s}$; for although it had begun to receive positive contributions from previously nonischemic sites (shaded) it also lost contributions from $(a)$ sites from the originally ischemic area whose average deflection began to decrease (solid) and (b) nonischemic sites overlying the RV which were initially positive but whose magnitudes declined towards zero after the subsequent large occlusion (see Table III).

Preocclusion TQ-ST segment deflection. While preocclusion control values for the TQ-ST deflection (TQ$\mathrm{ST}_{0}$ ) closely approached an isoelectric value for the animal population as a whole (TQ-ST $=+0.05 \pm 0.10 \mathrm{mV}$ ), the values in individual animals and at different electrode sites showed greater variation. This is illustrated in Fig. 7. The SEM for TQ-ST T $_{0}$ at all sites in a single animal was regularly $0.10 \mathrm{mV}$ while the mean was 
often significantly different from zero (either positive or negative) depending upon the animal studied (dark circles).

Nonspatial influences. The effect of progressive hyperkalemia ( 3.0 to $8.0 \mathrm{mM}$ ) on the evolution of the TQ-ST segment deflection was studied in six animals. Results in a representative animal are shown in Fig. 8. The average $\Delta$ TQ-ST recorded from all ischemic and nonischemic regions decreased with steadily increasing plasma potassium levels varying in a linear fashion with the logarithm of the $\left[\mathrm{K}^{+}\right]_{0}$ level $(r=0.974 \pm 0.013)$. The value of $\left[\mathrm{K}^{+}\right]_{0}$ at which no changes in TQ-ST segment are expected was found by extrapolation to be $8.72 \pm 0.15 \mathrm{mM}(n=5)$. Changes in whole ventricu- lar dynamics did not change significantly in this study until $\left[\mathrm{K}^{+}\right]_{0}$ exceeded $8.0 \mathrm{mM}$. By this time the TQ-ST segment changes were nearly nonexistent. To insure that the effect of $\mathrm{K}^{+}$on the TQ-ST deflection was nonspatially mediated, in the sixth animal the polyethylene occluder was brought out of the chest cavity, saline-soaked gauze pads were placed around the heart (to insure proper conductive pathways to the precordium), and the chest was closed. Needle electrodes were then placed under the skin at various points on the right and left precordium. With 11 repeated coronary occlusions at varying $\left[\mathrm{K}^{+}\right]_{0}$ levels the $\triangle \mathrm{TQ}$-ST again declined in a logarithmic manner $(r=0.98)$.
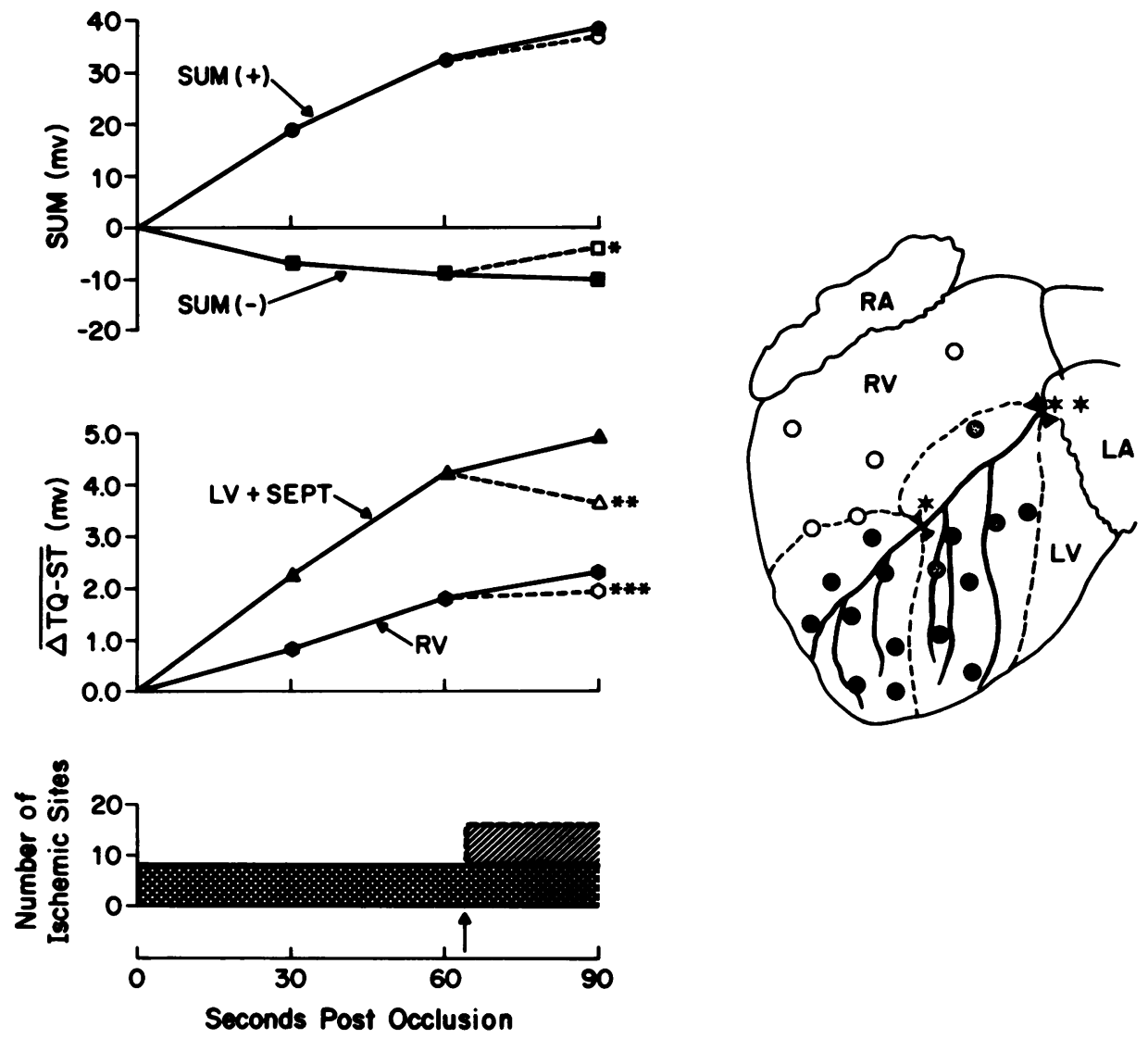

FIGURE 6 Effect of a sudden increase in ischemic area on the TQ-ST segment deflection. Average change in the TQ-ST segment $(\overline{\Delta T Q-S T})$ was measured at all sites at 30 and $60 \mathrm{~s}$ after seven repeated small artery occlusions (one star; solid symbols) in one animal. During occlusions $1,3,5$, and 7 the ischemia was maintained for $100 \mathrm{~s}$ and the $\overline{\Delta T Q-S T}$ at $90 \mathrm{~s}$ also measured. During occlusions 2, 4, and 6 the large artery was occluded at $65 \mathrm{~s}$ and $\overline{\Delta T Q-S T}$ again measured at $90 \mathrm{~s}$ (two stars; clear symbols). Despite the increase in ischemic area as evidenced by the doubling in the number of ischemic sites, the $\overline{\Delta T Q-S T}$ at all ischemic sites in the distribution of the occluded small artery (dark circles) declined in magnitude within the following $25 \mathrm{~s}$. SUM $+(\Theta)$, the sum of all positive $\triangle T Q-S T$ at all sites remained unchanged after the large artery occlusion while the sum of the negative $\Delta T Q-S T, S U M-(\square)$, rapidly declined. Dashed lines indicate ischemic boundary after small and large artery occlusions. ${ }^{*} P<0.001$ (unpaired $t$-test). ${ }^{* * P}<0.01$ and ${ }^{* * * P}<0.05$ (paired $t$ test at individual ischemic sites). See text for additional discussion. 


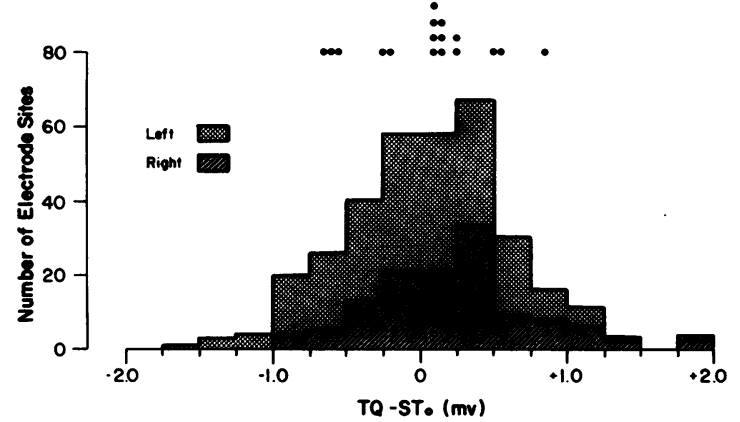

Figure 7 Deflections from the isoelectric line in the epicardial electrogram recorded before coronary artery occlusion (TQ-ST $_{0}$ ). TQ-ST $\mathrm{T}_{0}$ values varied among different animals and electrode sites. Histogram constructed from measurements of the TQ-ST deflection at all electrode sites and in all animals used in the compilation of the data in Table II. The main trunk of the anterior descending artery divided right from left ventricular sites, however, neither spatial nor hemodynamic factors were thought to be responsible for these variations. Although the mean of this population is close to zero, the mean of the deflections in individual animals (O) did, in some instances, assume values which were significantly different from zero.

\section{DISCUSSION}

Spatial influences and epicardial mapping. After acute coronary artery occlusion in the pig TQ-ST segment deflection changes ( $\Delta \mathrm{TQ}-\mathrm{ST}$ ) during early ischemia may be recorded from all epicardial regions of the heart. This and earlier studies $(12,35-37)$ have demonstrated that the relative magnitudes and polarities of these deflections in each animal are determined primarily by $(a)$ the position of the recording electrode with respect to the ischemic tissue boundaries; $(b)$ the area of ischemic involvement; (c) the transmural shape of ischemic involvement; and $(d)$ the thickness of the ventricular wall at the boundary.

Spatial factors which affect the TQ-ST segment deflection may be investigated in a physiologic and quantitative fashion by way of solid angle analysis. Predictions obtained from this analysis may then be tested and validated in the intact pig heart, a model which permits production and measurement of a standardized and well-defined area of ischemic involvement.

Boundary location in anterseptal ischemia. Although it was assumed that negative TQ-ST segment deflections should be recorded from both right and left ventricular nonischemic regions, the finding of positive deflections on the RV came initially as a surprise. This finding indicated that the spherical heart model with an ischemic region of uniform wall thickness from which the theoretical curves were derived (see Appendix) rather incompletely characterized the geom- etry of the anteroseptal region produced experimentally. A closer look at this geometry suggested that three different boundaries were present: right, left, and septal ventricular boundaries. Each of these boundaries would make its own contribution to the total TQ-ST segment deflection recorded at each electrode site. In Fig. 9, the positions of the boundaries are depicted in a theoretic heart model containing an ischemic region of $18 \mathrm{~cm}^{2}$ in area. Also shown are solid angle values calculated for a number of ischemic and nonischemic sites. It is observed that electrodes positioned over the ischemic region subtend positive solid angles, the magnitudes of which are influenced by the electrodes proximity to the different ischemic boundaries and the boundaries' thicknesses. Thus, the solid angle increases as the thicker LV boundary is approached (LV > septum > RV) as did the TQ-ST segment deflections in the experimental model. Electrodes positioned over nonischemic regions, however, sense current flow from different directions and thus the polarity and magnitudes of their solid angles

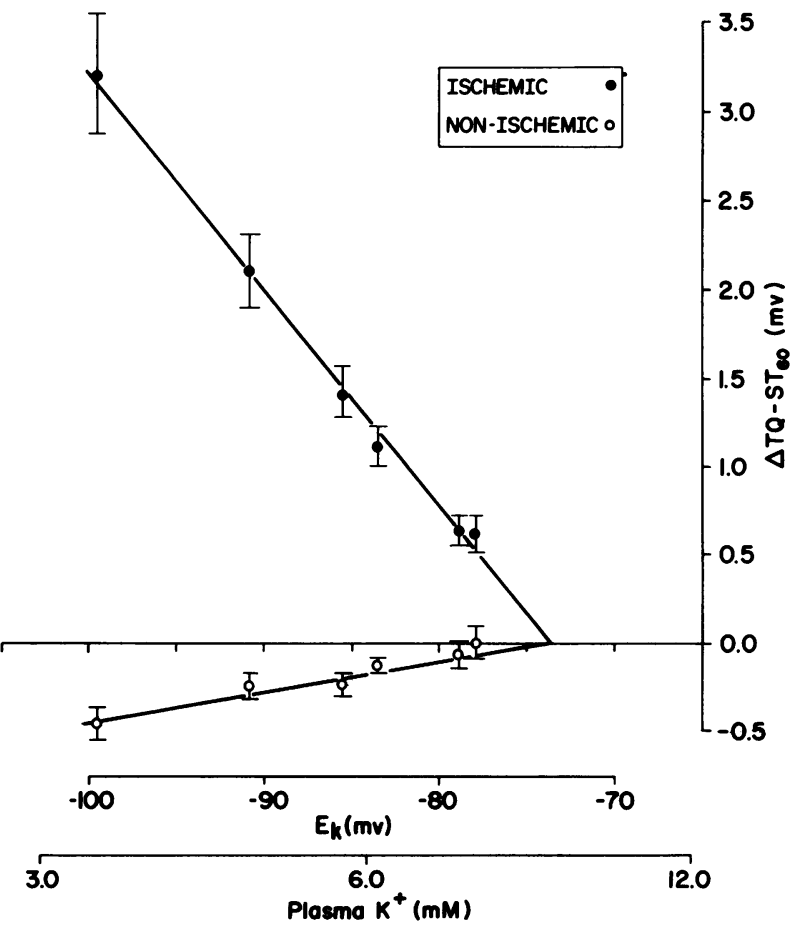

FIGURE 8 Plot of changes in the TQ-ST segment deflection recorded during multiple occlusions of the anterior descending artery in the pig at steadily increasing plasma potassium $\left(\mathrm{K}^{+}\right)$levels. The $\Delta \mathrm{TQ}-\mathrm{ST}$ recorded from both ischemic (cyanotic and nonischemic (left ventricle only) sites appeared to vary in a linear fashion with the transmembrane potential $\left(E_{k}\right.$ calculated from the Nernst equation at $37^{\circ} \mathrm{C}$, assuming intracellular $\left[\mathrm{K}^{+}\right]=140 \mathrm{mM}$ ) and with the log of the $\mathrm{K}^{+}$level. Values are means \pm SEM. Number of electrodes overying ischemic and schemic areas were 10 and 7 , respectively. 
reflect the difference (as opposed to the sum when the electrodes overlie the ischemic region) of contributions from the different boundaries. At nonischemic RV sites, despite the nearby contribution from the thinwalled RV boundary, the more distant, but thicker, septal and LV boundaries subtend the larger solid angles and therefore, as seen experimentally, positive TQ-ST segment deflections may be recorded from this nonischemic region (electrode sites $\mathrm{B}$ and $\mathrm{C}$ ).

Since spatial influences on the TQ-ST deflection depend upon the position of the electrode to the various boundaries, movement of the LV boundary to a more distant location should result in the following. First, the positive voltage at the RV nonischemic sites should eventually become negative if the boundary is moved far enough. Second, the positive potentials of the ischemic regions should decrease in magnitude. Finally, the LV nonischemic sites should become slightly more negative. In the experimental model such a relocation of the LV boundary was accomplished by proximally occluding the LAD artery, therby creating a larger area of ischemia. The results (Table III and Fig. 6) fulfilled these expectations.

Boundary vs. local influences on the TQ-ST segment deflection. Recognizing that it is the relationship of the electrode to the ischemic boundary which determines the relative magnitude and polarity of the TQ-ST segment deflection, only then can it be appreciated that although sites of TQ-ST segment elevation are usually found to overlie tissue exhibiting lactate production (38), ATP and CPK depletion (29, $38,39)$, histologic abnormalities $(31,40)$, QRS complex alterations $(5,30,41)$ and lowered $\mathrm{pO}_{2}(42-$ 44 ), contractile activity (45), and coronary blood flow (46-48), the frequent lack of quantitative relationships existing between the magnitude of the TQ-ST segment deflection at a particular site and these alternated markers should not be surprising. Although the magnitude of the TQ-ST deflection varies depending upon the electrode's orientation to the boundary, there is no reason to expect CPK levels, histology, etc., to vary in the same manner. Recent studies in which TQ-ST segment magnitudes at individual sites on the epicardium were compared to later changes $(24 \mathrm{~h})$ seen in tissue blood flow (49), histologic abnormalities (40), and CPK levels (49) at the same site, demonstrate the absence of such quantitative relationships.

Electrode location and ischemic shape. Further appraisal of the solid angle concept reveals additional spatial factors such as heart size and ischemic shape which may influence the polarity as well as the magnitude of the TQ-ST deflection. Differences in ischemic shape, first considered by Prinzmetal et al. (50), provide a good example of how solid angle analysis is most useful when employed in a quantitative manner. Some of the most difficult conceptual problems with
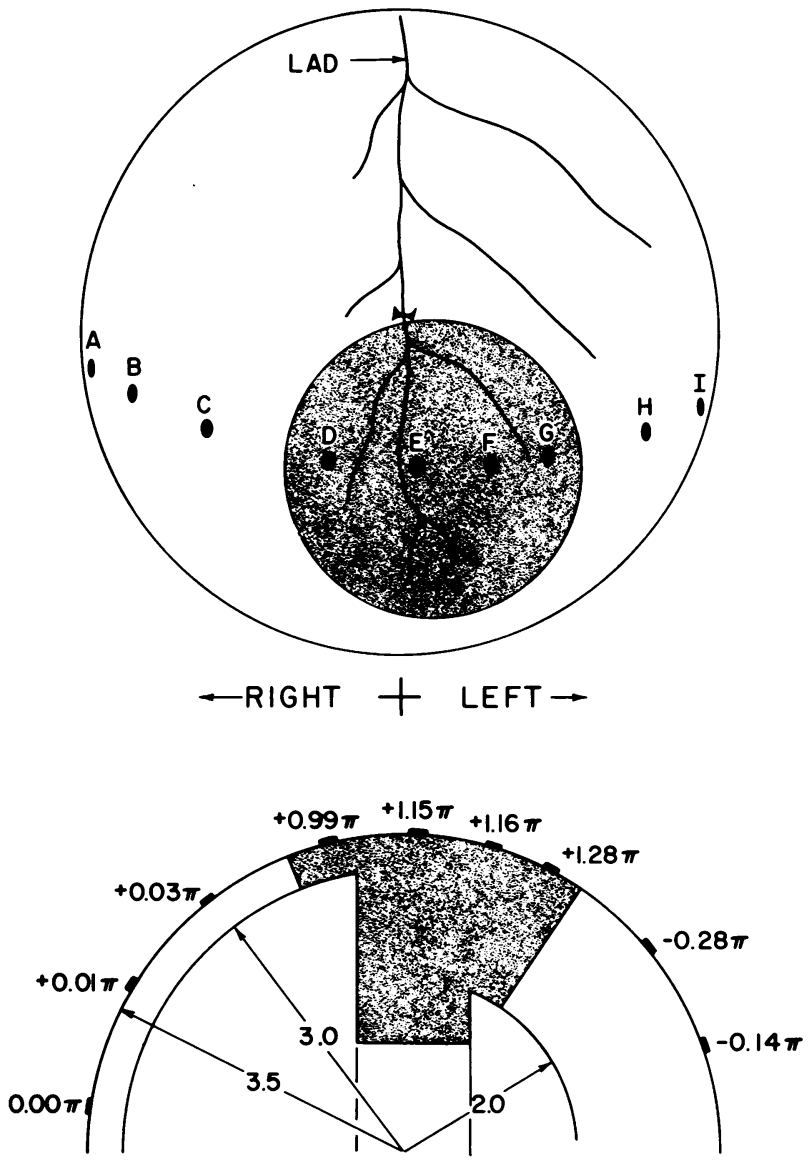

FIGURE 9 Solid angle values computed at ischemic (shaded area) and nonischemic sites during anteroseptal ischemia in a theoretical model of the heart. Area of ischemic involvement equaled $18 \mathrm{~cm}^{2}$. Distribution of solid angle values approximates TQ-ST deflections observed experimentally (Fig. 1 and Table II). Note that positive solid angle values may be obtained from electrodes overlying nonischemic portions of the right ventricle (sites B and C). Appreciation of the significant contribution of left ventricular sites may not be gained from this two dimensional (lower) view of ischemic segment. Much of the left ventricular boundary is considerably closer and right ventricular boundary farther away from these sites as the upper view may suggest.

the solid angle or boundary concept developed because of experimental data which did not appear to agree with predictions obtained from a rather superficial solid angle analysis. The following were held by some to be unreconcilable with the boundary concept: (a) TQ-ST segment elevation was observed in intramyocardial electrode leads when no corresponding change was recorded from epicardial leads (51); (b) An absence of TQ-ST depression was noted in intracavitary leads despite the finding of TQ-ST elevation at epicardial sites $(52,53)$; and (c) TQ-ST elevation was observed at both endocardial and epicardial locations when equal inner and outer wall 

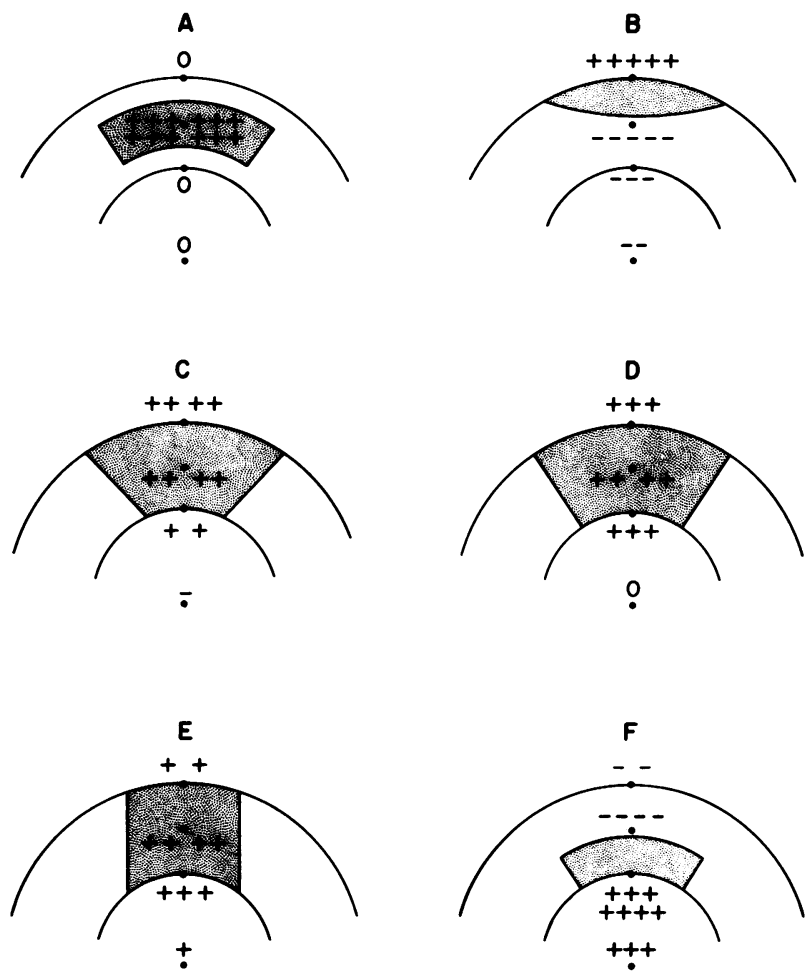

FIGURE 10 Polarity and relative magnitude of TQ-ST segment deflections computed at epicardial intramyocardial, endocardial, and intracavitary locations and various shapes of ischemic involvement. + (-)TQ-ST segment deflection indicates negative (positive) TQ segment and positive (negative) ST segment displacement. Dark circles refer to electrode positions.

(transmural) ischemic involvement was present (32). The last of these observations was distressing to many at the time (1942), including of all people Bayley (54), but Pruitt and Valencia (35) showed rather clearly a few years later that there was "a simple, if initially elusive, explanation" (32) provided by the proper application of the solid angle concept. Such an application is illustrated in Fig. 10, where polarities and relative magnitudes of solid angles (TQ-ST segment deflections) were computed for different electrode locations and ischemic shapes. The first situation mentioned above can be explained by postulating a patchy ischemic involvement (Fig. 10A), a quite common finding in normal dogs (55) and patients with advanced coronary artery disease (56). The second and third merely require a transmural ischemic shape (Fig. 10C, $\mathrm{D}$, and $\mathrm{E}$ ).

Well-delineated and diffuse ischemic boundaries. As shown in Fig. 4, the solid angle increases as an epicardial electrode is moved from the center to the periphery of the ischemic region, provided that the boundary is well delineated (zero width) and the thickness of the ventricular wall is constant. In the pig (23), baboon (57), and normal human $(58,59)$, there existed few functionally significant collateral vessels and one expects the boundary to be narrow and well defined (24). However, in the dog, with its richer collateral blood supply (23), evidence suggests that the boundary lacks such definition (60). In this species a wide gradient of transmembrane potentials most likely exists at the periphery of the ischemic region and the boundary or separation between ischemic and nonischemic tissue is wider and much less distinct (18).

The influence of boundary width on the distribution of solid angle values at ischemic and nonischemic sites is shown in Fig. 11. Although different boundary widths do not alter the precordial distribution, changes in the epicardial distribution in the vicinity of the boundary are seen. When the boundary is wide, solid angle values now decrease, instead of increasing, as electrodes are moved from the center to the periphery of the ischemic region.

One would expect this difference in the solid angle distribution from the center to the periphery of the ischemic region to be reflected by differences in the TQ-ST segment voltages in species with (e.g., pig and baboon) and without (e.g., dog) a well-defined boundary. Studies in the dog have shown that the TQST segment deflection is greater in the center of the ischemic region than at the periphery (61). Studies in the baboon, on the other hand, show only a rapid transition in polarity as electrodes are moved from the ischemic to the nonischemic region (15). The lack of uniform wall thickness of the anteroseptal ischemic region and the size of the electrodes did not permit us to investigate the possibility that TQ-ST segment deflections might actually increase as the boundary is approached in the pig. The suggestion that the boundary is both diffuse and dependent upon collateral blood flow in the dog raises a number of interesting possibilities. First, precise localization of the boundaries of the ischemic region is less likely to be accomplished in the dog than in the pig. Second, one would expect the width of this boundary to depend upon collateral vessel patency and perfusion pressure as suggested by Bayley (18). Finally, one would also expect that the area of ischemic involvement might be modified in the dog by interventions which either alter the level of collateral blood supply to this wide boundary or the oxygen demands of the tissue at the boundary. In comparison, in the pig such modification might not be possible. Here the amount of tissue becoming ischemic closely approaches that normally perfused by the occluded artery (Table I). Modification of eventual infarct size in humans may similarly depend upon available collateral flow.

Spatial influences and precordial mapping. Although solid angle analysis was carried out for both precordial and epicardial locations, experimental veri- 


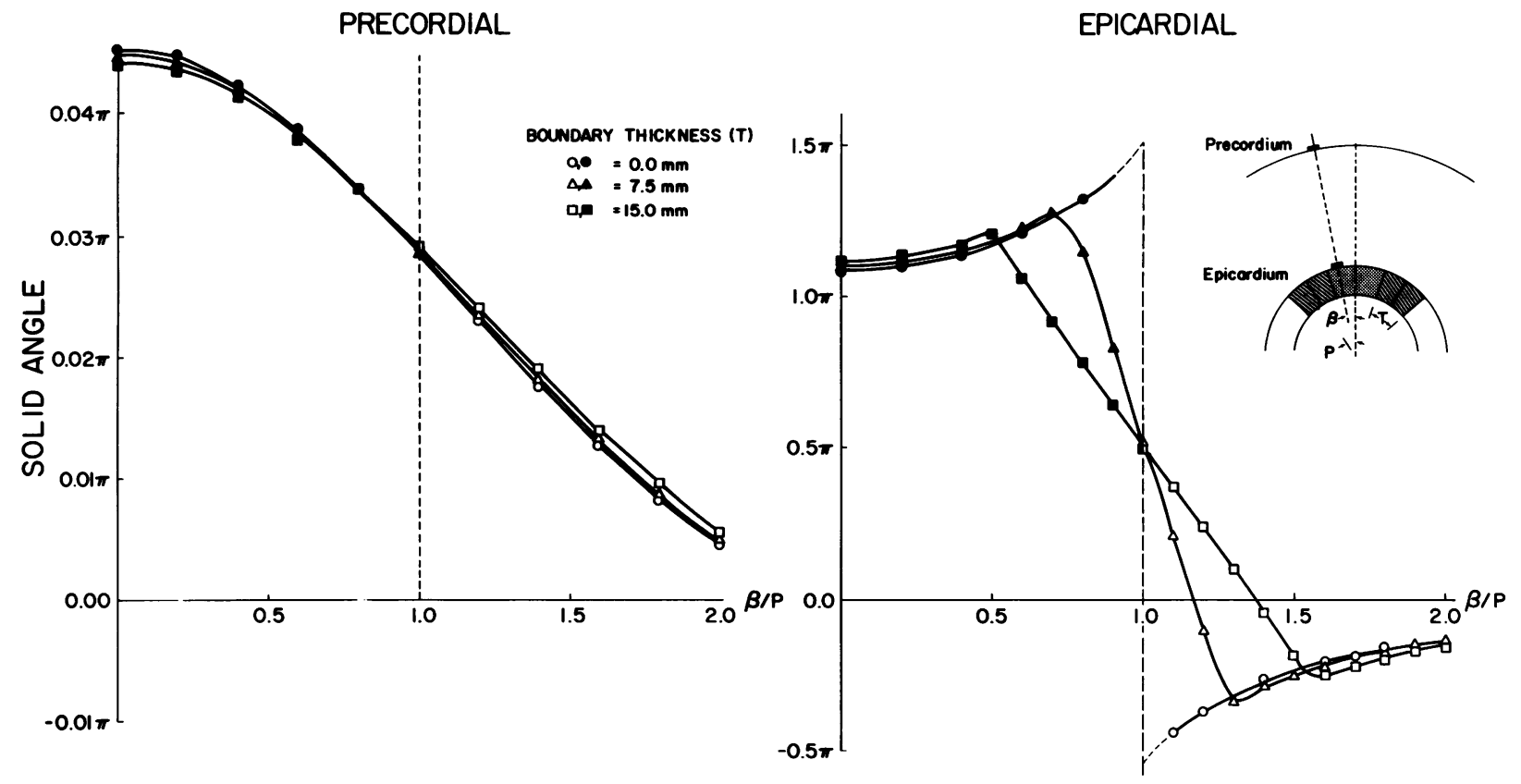

FIGURE 11 Influence of boundary thickness (T) on the polarity and magnitude of the solid angle computed at precordial and epicardial locations. Area of ischemic involvement equaled $13.8 \mathrm{~cm}^{2}(\mathrm{P}=0.50$ radians $)$. At the precordium, whether the boundary is well defined $(T=0)$ or diffuse $(T=15 \mathrm{~mm})$, the solid angle values are essentially unchanged. At the epicardium, differences in solid angle values for the well-defined and diffuse boundaries occur only in the region of the boundary. Although solid angle values in the ischemic region increase in magnitude as a distinct boundary is approached, they decrease when the boundary is wide and diffuse. See text for additional discussion.

fication was limited to the latter. In this instance the polarity and magnitude of the TQ-ST segment at each site could be associated with the position the electrode maintained with respect to the ischemic region. Similar verification at precordial sites though desirable will be difficult to accomplish. Not only does the distance from the electrode to the heart's surface vary depending upon the electrodes' position on the precordium, but whether changes in ischemic area and shape, heart size, etc., decrease or increase the magnitude of the TQ-ST deflection depends in turn upon this distance. This matter has received little attention despite its significant influence on the magnitude of the TQ-ST deflection. For instance, a change in the precordial-to-heart distance of only $1 \mathrm{~cm}$ (i.e., from 5 to 6 $\mathrm{cm}$ ) may reduce the magnitude by over $40 \%$. Similar variations in this distance may occur in a variety of physiologic (posture, pregnancy, etc.) and pathologic (pulmonary congestion, pneumothorax, cardiac dilatation, etc.) conditions.

TQ-ST segment data obtained at the precordium which does suggest general agreement with solid angle analysis include observations that: $(a)$ the magnitude of the precordial TQ-ST segment deflection increases with increases in ischemic area $(12,62)$; and $(b)$ maximal precordial TQ-ST segment deflections are recorded over the center of the ischemic region, decreasing at more peripheral locations $(5,63)$.

Nonspatial influences on the TQ-ST segment deflection. According to the solid angle theorem (Fig. 1), the TQ-ST segment deflection is also a function of the difference in transmembrane voltage existing between the normal $\left(V_{m_{\mathrm{N}}}\right)$ and ischemic $\left(\mathrm{V}_{\mathrm{m}_{\mathrm{r}}}\right)$ cells during both diastole (TQ segment) and systole (ST segment). During early ischemia this difference is believed to arise primarily as a consequence of anoxia and potassium leakage out of the ischemic cells, and its accumulation in the surrounding extracellular space $(13,32,64,65)$. If the difference in transmembrane voltage between the normal and ischemic cells widens, the TQ-ST deflection magnitude increases. If, for any reason, these differences disappear, then so must the TQ-ST deflection.

The number of potential interventions and mechanisms by which the TQ-ST segment deflection may be modified in a nonspatial manner is large and diverse. These would include factors which directly modify the transmembrane potentials of either the normal or ischemic cells during diastole or systole (e.g., electrolytes, temperature, catecholamines, heart rate, metabolic inhibitors, and anti-arrhythmic therapy). Also included are agents which alter the transmem- 
brane voltage of the ischemic tissue by changing the rate and degree of potassium leakage out of these cells. In the presence of ischemia-inhibited $\mathrm{Na}^{+}-\mathrm{K}^{+}$ ATPase pump, chronotropic (66), inotropic (catecholamines [30, 67], ouabain [68], calcium [69]), and metabolic (hyperthermia [70], acidosis [71]) factors serve to accelerate potassium efflux. This facilitates potassium accumulation in the extracellular space of the ischemic tissue and causes the diastolic resting potential to decline and the action potential duration to shorten. Factors which slow potassium loss (e.g., hypothermia, potassium solutions, and myocardial depressants) may help to restore the transmembrane potential of the ischemic cells back to more normal values.

The possibility, therefore, that a change in the ischemic TQ-ST segment deflection elicited by a given intervention can be reliably and exclusively attributed to a change in the spatial geometry of the ischemic region (ischemic area and shape) and not to a nonspatial change in the transmembrane potential difference $\left(\Delta V_{m}\right)$ between the two tissues would seem to be unlikely. For example, one indication that propranolol may benefit patients with angina pectoris is the observation that it decreases the magnitude of the ischemic TQ-ST segment deflection $(29,72)$. Hemodynamically, propranolol decreases heart rate and the force and velocity of contraction (73). In this way it may reduce demands of the ischemic tissue, and may, as shown in the dog (74), help to decrease ischemic area. As shown earlier (Figs. 3-5), at the precordium a decrease in ischemic area will decrease the solid angle and the TQ-ST deflection magnitude $(12,62)$. There are other, nonspatial ways, however, in which propranolol may decrease the deflection. As suggested by the work of Sarnoff et al. (75), Parker et al. (66), and Polimeni and Vassalle (76), decreases in oxygen consumption will also decrease the rate of potassium leakage and accumulation in the ischemic region. This in turn will limit the development of $\Delta V_{m}$ and the TQ-ST deflection magnitude will decline. Specific electrophysiologic actions of propranolol may also affect $\Delta \mathrm{V}_{\mathrm{m}}$. Kupersmith et al. (77) and Wittig and Williams (17) found that propranolol returns the action potential duration of ischemic cells back towards normal. The systolic $\Delta V_{m}$, therefore, is reduced, resulting in a decline in the ST and total TQ-ST segment deflection. This effect of propranolol may be related to its ability to antagonize catecholamine effects on calcium currents across the myocardial membrane (78). The mechanism by which verapamil, a specific calcium current blocker, reduces the ischemic TQ-ST segment may be similar $(79,80)$.

Potassium ion infusion was chosen for this study because it has minimal effects on oxygen consumption and contractile activity of the heart while having significant electrophysiologic actions. Potassium can (a) directly alter the transmembrane potential (depolarizes cells during diastole and shortens their action potential duration during systole [81]); (b) influence the rate of potassium leakage and accumulation in the extracellular apace (stimulates uptake by the cell of potassium ion [82]); and (c) increase potassium conductance (83). The precise mechanism by which potassium infusion reduced the magnitude of the TQ-ST segment deflections in this study cannot be ascertained without making simultaneous measurements of transmembrane potentials before and during coronary artery occlusion in the normal and ischemic regions. The possibility that some of the changes in the TQ-ST segment may be due to hyperkalemic changes in conduction velocity $(30)$ should also be investigated. The finding that the decline in the TQ-ST deflection appeared to vary in a linear fashion with the logarithm of $\mathrm{K}^{+}$level is interesting, however, for both $E_{K}$ and the action potential duration (which correspond to the TQ and ST segments of the electrogram) both vary with the $\log$ of $\mathrm{K}^{+}$. The latter discovery was made by examining data from Surawicz' original study (84) and then plotting action potential duration versus the $\log$ of $\mathrm{K}^{+}$; the resultant curve was remarkably linear over the range of $\mathrm{K}^{+}$values from 2.0 to $10.00 \mathrm{mM}(r=0.992)$. The finding that changes in the TQ-ST segment were similar at either nonischemic or ischemic regions on the epicardium and precordium suggests that potassium exerts a primarily nonspatial influence on the TQ-ST segment and thus is not dependent upon either electrode location or ischemic geometry. This nonspatial influence of potassium may help to account for any previously observed absences of TQ-ST deflections in the ECG from the acute myocardial infarction patient who is also in renal failure (85), as well as suggest an alternate mechanism by which glucose-insulin-potassium improves the ECG picture of patients with an acute myocardial infarction (86).

Preocclusion TQ-ST segment deflections. The cause of control (preocclusion) TQ-ST deflections above or below zero in a normal animal or man is not known $(87,88)$. In this study heart rate was kept constant (89) and electrode artifact, if present, would presumably account only for positive deflections. Since neither spatial (right vs. left ventricular sites) nor hemodynamic correlation apparently accounted for this variation, it is assumed that slight changes in the temperature at the epicardial surface, because of the openchest preparation, might be responsible $(90,91)$. The conventional view, therefore, that the normal TQST segment is isoelectric, is not supported by this study.

Solid angle theory and the experimental model. The solid angle theorem employed in this study is a 

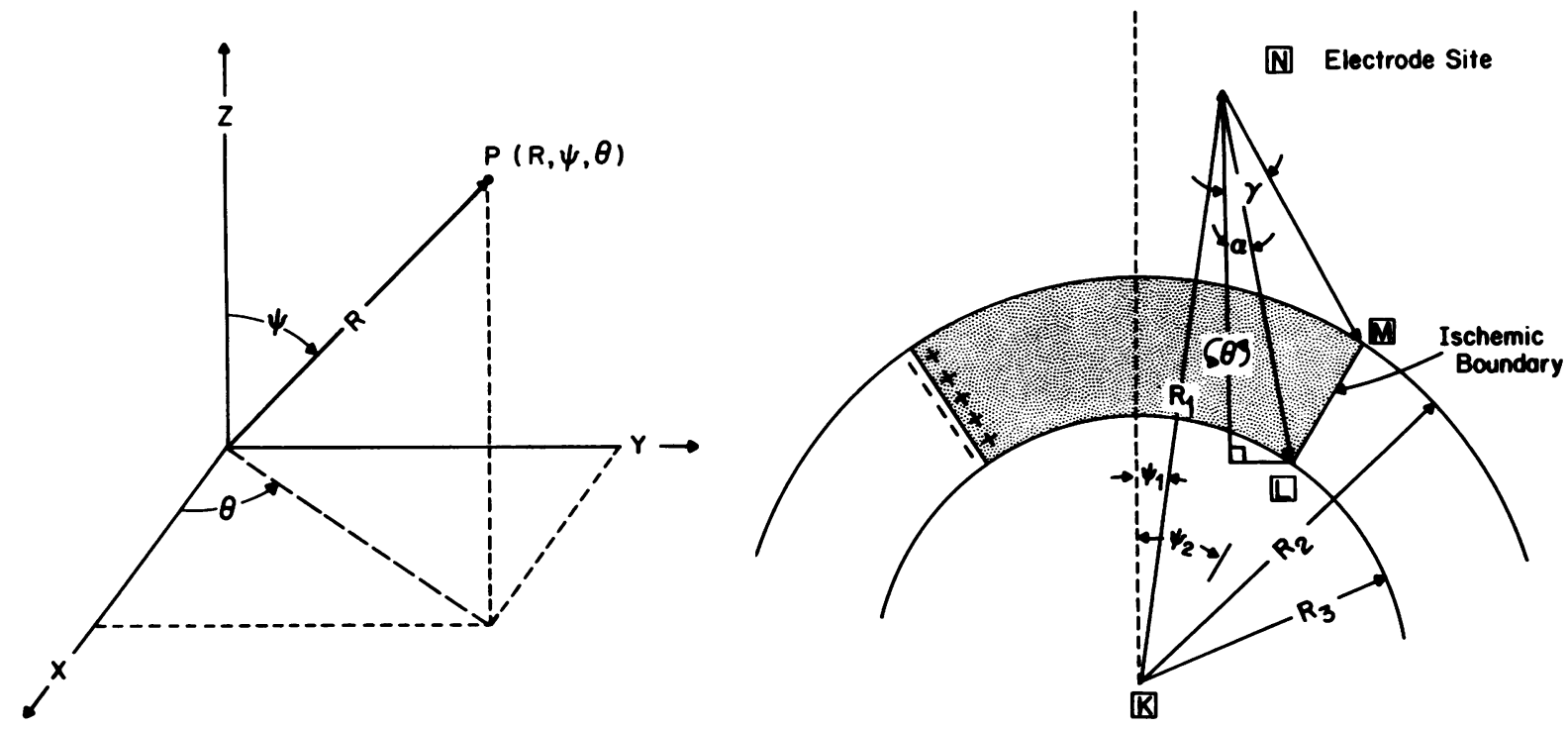

FIGURE 12 Left. Relationship between spherical and rectangular coordinates of a point $\mathrm{P}$ in space. Right. Model of transmural ischemic region in the ventricular wall during electrical systole used in solid angle computations.

mathematical expression which relates the potential recorded at an electrode site to the flow of currents in homogeneous volume conductors of infinite extent. Its conception can be traced at least as far back as Helmholtz in 1853 (92) and was utilized extensively in the formulation of modern electrocardiographic theory by Wilson and Bayley (93) and McFee and Johnston (94). It requires that the recording electrode and excitable tissue both be located in a homogeneous conductor of infinite extent. However, in both clinical (precordium) and experimental (epicardium) situations the boundaries are finite and the substances surrounding the heart (skin, bones, lung, blood) of somewhat varying conductivity. These factors, however, may tend more to alter the absolute magnitude of the electrocardiographically recorded potentials than their relative distribution $(18,95)$. For example, Bayley showed that the potential at a point on a volume conductor of arbitrary shape (as in the case of the thorax) is approximately twice the value obtained at the same point were the volume conductor infinite in extent (18). A review of the advantages and limitations of solid angle analysis as related to ECG interpretation has recently been written (19).

Summary and conclusions. The TQ-ST segment deflection arises due to differences in transmembrane potential at the boundary between normal and ischemic tissue during diastole and systole. Nonspatial factors influence the magnitude of this potential gradient, while spatial factors alter the relative position of the boundary to the electrode site. Spatial factors including electrode location, ischemic area and shape, heart size, and wall thickness can be quantitatively analyzed with the solid angle theorem and then experimentally verified in the intact porcine heart, a model which permits production and measurement of a well-defined area of ischemic involvement. Nonspatial influences are of equal importance, though less easily analyzed in a theoretical fashion. One such influence, the elevation of plasma $\mathrm{K}^{+}$levels, results in a decrease in the magnitude of the TQ-ST deflections recorded from both ischemic and nonischemic portions of the heart after coronary artery occlusion. The majority of pharmacologic agents previously shown to influence the TQ-ST segment deflection during ischemia probably do so via both spatial and nonspatial mechanisms.

\section{APPENDIX}

Spherical coordinate transform. The spherical coordinates $(R, \psi, \theta)$ of a point $P$ in space are illustrated in Fig. 12 (left). Rectangular coordinates $(X, Y, Z)$ are related to spherical coordinates by the equations:

$$
\mathrm{X}=\mathrm{R} \sin \psi \cos \theta ; \mathrm{Y}=\mathrm{R} \sin \psi \sin \theta ; \mathrm{Z}=\mathrm{R} \cos \psi
$$

The distance $\overline{\mathrm{AB}}$ between two points in space $A\left(X_{1}, Y_{1}, Z_{1}\right)$ and $\mathrm{B}\left(\mathrm{X}_{2}, \mathrm{Y}_{2}, \mathrm{Z}_{2}\right)$ can be obtained by the equation:

$$
\overline{\mathrm{AB}}=\left[\left(\mathrm{X}_{1}-\mathrm{X}_{2}\right)^{2}+\left(\mathrm{Y}_{1}-\mathrm{Y}_{2}\right)^{2}+\left(\mathrm{Z}_{1}-\mathrm{Z}_{2}\right)^{2}\right] \mathbf{1}
$$

Solid angle computations. In Fig. 12 (right) a small segment of ventricular wall is diagrammed illustrating the normal and ischemic (shaded) myocardial tissue with the boundary between them. The solid angle constructed at the electrode site $\mathrm{N}$ by the ischemic boundary may be computed from:

$$
\Omega=\int_{0}^{2 \pi}[\cos \alpha-\cos \gamma] \cdot d \theta
$$


where $\alpha$ and $\gamma$ are obtained from the Cosine Law or:

$$
\begin{gathered}
\alpha=\cos ^{-1}\left[\left(\overline{\mathrm{KL}}^{2}-\overline{\mathrm{KN}}^{2}-\overline{\mathrm{LN}}^{2}\right) \pm / 2 \cdot \overline{\mathrm{KN}} \cdot \overline{\mathrm{LN}}\right] \\
\quad \text { and } \\
\gamma=\cos ^{-1}\left[\left(\overline{\mathrm{LM}}^{2}-\overline{\mathrm{MN}}^{2}-\overline{\mathrm{KN}}^{2}\right) \mathbf{t} / 2 \cdot \overline{\mathrm{MN}} \cdot \overline{\mathrm{KN}}\right] .
\end{gathered}
$$

\section{ACKNOWLEDGMENTS}

This work was supported by U. S. Public Health Service grants 5P50 HL 17648 and HL 7013202, the Louis Block Fund, and Sinton Charitable Associates of the University of Chicago.

\section{REFERENCES}

1. Shaefer, H., and H. G. Haas. 1962. Electrocardiography. Handb. Physiol. 1 (Sect. 2. Circulation): 380.

2. Wilson, F. N., F. D. Johnston, I. G. W. Hill, and G. C. Grout. 1933. The electrocardiogram in the later stages of experimental myocardial infarction. Trans. Assoc. Am. Physicians Phila. 48: 154-163.

3. Nielsen, B. L. 1973. ST-segment elevation in acute myocardial infarction. prognostic importance. Circulation. 48: $338-345$.

4. Braunwald, E., and P. R. Maroko. 1974. The reduction of infarct size - an idea whose time (for testing) has come. Circulation. 50: 206-209.

5. Muller, J. E., P. R. Maroko, and E. Braunwald. 1975. Evaluation of precordial electrocardiographic mapping as a means of assessing changes in myocardial ischemic injury. Circulation. 52: 16-27.

6. Flaherty, J. T. 1976. Clinical uses of precordial STsegment mapping and the pathophysiology of ST-segment voltage changes. Circulation. 53 (Suppl. I): 85-87.

7. Ross, J., Jr. 1976. Electrocardiographic ST-segment analysis in the characterization of myocardial ischemia and infarction. Circulation. 53 (Suppl. I): 73-81.

8. Holland, R. P., and H. Brooks. 1975. ST segment mapping: Fact and fallacy. Circulation. 52 (Suppl. II): 6. (Abstr.)

9. Norris, R. M., C. Barratt-Boyes, M. K. Heng, and B. N. Singh. 1976. Failure of ST segment elevation to predict severity of acute myocardial infarction. Br. Heart J. 38: 85-92.

10. Fozzard, H. A., and D. S. DasGupta. 1977. ST segment potentials and mapping: Theory and experiment. Circulation. 54: 533-537.

11. Reese, L., S. Scheidt, and T. Killip. 1973. Variability of precordial ST segment maps after acute myocardial infarction in man. Circulation. 48 (Suppl. IV): 38. (Abstr.)

12. Holland, R. P., and H. Brooks. 1975. Precordial and epicardial surface potentials during myocardial ischemia in the pig. A theoretical and experimental analysis of the TQ and ST segments. Circ. Res. 37: 471-480.

13. Holland, R. P., and H. Brooks. 1977. TQ-ST segment mapping: A critical review and analysis of current concepts. Am. J. Cardiol. In press.

14. Samson, W. E., and A. M. Scher. 1960. Mechanism of S-T segment alteration during acute myocardial injury. Circ. Res. 8: 780-787.

15. Bruyneel, K. J. J. 1975. Use of moving epicardial electrodes in defining ST-segment changes after acute coronary occlusion in the baboon. Relation to primary ventricular fibrillation. Am. Heart J. 89: 731-741.

16. Cohen, D., and L. A. Kaufman. 1975. Magnetic determination of the relationship between the $S-T$ segment shift and the injury current produced by coronary artery occlusion. Circ. Res. 36: 414-424.

17. Wittig, J. H., and E. M. V. Williams. 1976. Mechanism of decrease of ST elevation by propranolol in ischemic myocardium. Circulation. 54 (Suppl. II): 15. (Abstr.)

18. Bayley, R. H. 1958. Electrocardiographic analysis. Biophysical Principles of Electrocardiography. Paul B. Hoeber, Inc., New York. 19-34, 184-196, and 207-222.

19. Holland, R. P., and M. F. Arnsdorf. 1977. Solid angle theory and the electrocardiogram. Physiologic and quantitative interpretations. Prog. Cardiovasc. Dis. In press.

20. Plonsey, R. 1969. Bioelectric Phenomena. McGraw-Hill Book Co., New York. 202-275.

21. Plonsey, R. 1974. An evaluation of several cardiac activation models. J. Electrocardiol. (San Diego). 7: 237244.

22. Howe, B. B., P. A. Fehn, and R. R. Pensinger. 1968 Comparative anatomical studies of the coronary arteries of canine and porcine heart. I. Free ventricular walls. Acta Anat. 71: 13-21.

23. Schaper, W. 1971. Comparative Arteriography of the Collateral Circulation of the Heart. North Holland Publishing Company, Amsterdam. 29-50.

24. Brooks, H., J. Al-Sadir, J. Schwartz, B. Rich, P. Harper, and L. Resnekov. 1975. Biventricular dynamics during quantitated anteroseptal infarction in the porcine heart. Am. J. Cardiol. 36: 765-775.

25. Van Citters, R. L., D. L. Franklin, and R. F. Rushmer. 1964. Left ventricular dynamics in dogs during anesthesia with alpha-chloralose and sodium pentobarbital. Am. J. Cardiol. 13: 349-354.

26. Lichtig, C., and H. Brooks. 1975. Myocardial ultrastructure and function during progressive early ischemia in the intact heart. J. Thorac Cardiovasc. Surg. 70: 309315.

27. Weiner, J. M., C. S. Apstein, J. H. Arthur, and W. B. Hood, Jr. 1974. Persistence of myocardial injury following brief periods of coronary occlusion. Am. J. Cardiol. 33: 177. (Abstr.)

28. Swain, J. A., H. G. Hanley, K. R. Genth, R. M. Lewis, C. J. Hartley, and A. Schartz. 1976. Prolonged depression of regional myocardial function following transient ischemia in conscious dogs. Physiologist. 19: 383. (Abstr.)

29. Maroko, P. R., J. K. Kjekshus, B. E. Sobel, T. Watanabe, J. W. Covell, J. Ross, Jr., and E. Braunwald. 1971. Factors influencing infarct size following coronary artery occlusions. Circulation. 43: 67-82.

30. Holland, R. P., and H. Brooks. 1976. The QRS complex during myocardial ischemia. An experimental analysis in the porcine heart. J. Clin. Invest. 57: 541550.

31. Ginks, W. R., H. D. Sybers, P. R. Maroko, J. W. Covell, B. E. Sobel, and J. Ross, Jr. 1972. Coronary artery reperfusion. II. Reduction of myocardial infarct size at 1 week after coronary occlusion. J. Clin. Invest. 51: 2717-2723.

32. Holland, R., F. Pashkow, and H. Brooks. 1974. Atraumatic epicardial electrode and rapid sampling switch for cardiac surface mapping. J. Appl. Physiol. 37: 424-427.

33. Redwood, D. R., E. R. Smith, and S. E. Epstein. 1972. Coronary artery occlusion in the conscious dog. Effects of alterations in heart rate and arterial pressure on the degree of myocardial ischemia. Circulation. 46: 323-332.

34. Snedecor, G. W., and W. G. Cochran. 1967. Statistical Methods. Iowa State University Press, Ames, Iowa. 6th edition. $593 \mathrm{pp}$.

35. Pruitt, R. D., and F. Valencia. 1948. The immediate electrocardiographic effects of circumscribed myocardial 
injuries: An experimental study. Am. Heart J. 35: 161197.

36. Hellerstein, H. K., and L. N. Katz. 1958. The electrical effects of injury at various myocardial locations. Am. Heart J. 36: 184-220.

37. Craib, W. H. 1927-29. A study of the electrical field surrounding active heart muscle. Heart. 14: 71-109.

38. Karlsson, J., G. H. Templeton, and J. T. Willerson. 1973. Relationship between epicardial S-T segment changes and myocardial metabolism during acute coronary insufficiency. Circ. Res. 32: 725-730.

39. Griggs, D. M., Jr., V. V. Tchokoev, and C. C. Chen 1972. Transmural differences in ventricular tissue substrate levels due to coronary constriction. Am. J. Physiol. 222: 705-709.

40. Irwin, R. G., and F. R. Cobb. 1976. Relationship between epicardial (Ep) ST segment changes and extent of histologic myocardial infarction (MI) in awake dogs. Circulation 54 (Suppl. II): 15. (Abstr.)

41. Hamlin, R. L., C. R. Smith, H. K. Pellerstein, and R. S. Pipers. 1969. Alterations in QRS during ischemia of the left ventricular free-wall in goats. J. Electrocardiol. (San Diego). 2: 223-228.

42. Sayen, J. J., W. F. Sheldon, G. Peirce, and P. T. Kuo. 1958. Polarographic oxygen, the epicardial electrocardiogram and muscle contraction in experimental acute regional ischemia of the left ventricle. Circ. Res. 6: 779798.

43. Sayen, J. J., G. Peirce, A. H. Katcher, and W. F. Sheldon. 1961. Correlation of intramyocardial electrocardiograms with polarographic oxygen and contractility in the nonischemic and regionally ischemic left ventricle. Circ. Res. 9: 1268-1279.

44. Khuri, S. F., J. T. Flaherty, J. B. O'Riordan, B. Pitt, R. K. Brawley, J. S. Donohoo, and V. L. Gott. 1975. Changes in intramyocardial ST segment voltage and gas tensions with regional myocardial ischemia in the dog. Circ. Res. 37: 455-463.

45. Ross, J., Jr., and D. Franklin. 1976. Analysis of regional myocardial function, dimensions, and wall thickness in the characterization of myocardial ischemia and infarction. Circulation. 53 (Suppl. I): 88-92.

46. Wégria, R., M. Segers, R. P. Keating, and H. P. Ward. 1949. Relationship between the reduction in coronary flow and the appearance of electrocardiographic changes. Am. Heart J. 38: 90-96.

47. Timogiannakis, G., I. Amende, E. Martinez, and M. Thomas. 1974. ST segment dediation and regional myocardial blood flow during experimental partial coronary artery occlusion. Cardiovasc. Res. 8: 469-477.

48. Smith, H. J., B. N. Singh, R. M. Norris, M. B. John, and P. J. Hurley. 1975. Changes in myocardial blood flow and S-T segment elevation following coronary artery occlusion in dogs. Circ. Res. 36: 697-705.

49. Heng, M. K., B. N. Singh, and R. M. Norris. 1975. Relationship between epicardial ST segment elevation and experimental infarct size. Circulation. 52 (Suppl. II): 6. (Abstr.)

50. Prinzmetal, M., H. C. Bergman, H. E. Kruger, L. L. Schwartz, B. Simkin, and S. S. Sobin. 1948. Studies on the coronary circulation. III. Collateral circulation of beating human and dog hearts with coronary occlusion. Am. Heart J. 35: 689-717.

51. Durrer, D., P. Formijne, R. T. Van Dam, J. Büller, A. A. W. Van Lier, and F. L. Meyler. 1961. In revived human fetal heart and in acute and chronic coronary occlusion. The electrocardiogram in normal and some abnormal conditions. Am. Heart J. 61: 303-316.
52. Wolferth, C. C., S. Bellet, M. M. Livezey, and F. D. Murphy. 1945. Negative displacement of the RS-T segment in the electrocardiogram and its relationships to positive displacement; an experimental study. Am. Heart J. 29: 220-245.

53. Ekmekci, A., H. Toyoshima, J. K. Kwoczynski, T. Nagaya, and M. Prinzmetal. 1961. Angina pectoris. IV. Clinical and experimental difference between ischemia with $S-T$ elevation and ischemia with S-T depression. Am. J. Cardiol. 7: 412-426.

54. Bayley, R. H. 1942. An interpretation of the injury and the ischemic effects of myocardial infarction in accordance with the laws which determine the flow of electric currents in homogeneous volume conductors, and in accordance with relevant pathologic changes. Am. Heart J. 24: 514-528.

55. Cohn, P. F., E. S. Kirk, J. M. Downey, E. H. Sonnenblick, and R. Gorlin. 1973. Autoradiographic evaluation of myocardial collateral circulation in the canine heart. Cardiovasc. Res. 7: 181-185.

56. Fulton, W. F. M. 1956. Chronic generalized myocardial ischaemia with advanced coronary artery disease. $\mathrm{Br}$. Heart J. 18: 341-354.

57. Grayson, J., and M. Irvine. 1968. Myocardial infarction in the monkey: Studies on the collateral circulation after acute coronary occlusion. Cardiovasc. Res. 2: 170-178.

58. Pitt, B. 1959. Interarterial coronary anastomoses. Occurrence in normal hearts and in certain pathologic conditions. Circulation. 20: 816-822.

59. Schlesinger, M. J. 1938. An injection plus dissection study of coronary artery occlusions and anastomoses. Am. Heart J. 15: 528-568.

60. Becker, L. C., R. Ferreira, and M. Thomas. 1973. Mapping of left ventricular blood flow with radioactive microspheres in experimental coronary artery occlusion. Cardiovasc. Res. 7: 391-400.

61. Ekmekci, A., H. Toyoshima, J. K. Kwoczynski, T. Nagaya, and M. Prinzmetal. 1961. Angina pectoris. V. Giant R and receding $S$ wave in myocardial ischemia and certain nonischemic conditions. Am. J. Cardiol. 7: 521-532.

62. Capone, R. J., A. S. Most, and P. A. Sydlik. 1975. Precordial ST segment mapping. A sensitive technique for the evaluation of myocardial injury. Chest. 67: 577-582.

63. Reid, D. S., L. J. Pelides, and J. P. Shillingford. 1971. Surface mapping of RS-T segment in acute myocardial infarction. Br. Heart J. 33: 370-374.

64. Johnson, E. A. 1976. First electrocardiographic sign of myocardial ischemia: An electrophysiological conjecture. Circulation. 53 (Suppl. I): 82-84.

65. Case, R. B., M. G. Nasser, and R. S. Crampton. 1969. Biochemical aspects of early myocardial ischemia. Am. J. Cardiol. 24: 766-775.

66. Parker, J. O., M. A. Chiong, R. O. West, and R. B. Case. 1970. The effect of ischemia and alterations of heart rate on myocardial potassium in man. Circulation. 42: 205-217.

67. Vassalle, M., and O. Barnabei. 1971. Norepinephrine and potassium fluxes in cardiac Purkinje fibers. Pfluegers Arch. Eur. J. Physiol. 322: 287-303.

68. Hajdu, S., and E. Leonard. 1959. The cellular basis of cardiac glycoside action. Pharmacol. Rev. 11: 173-209.

69. Nayler, W. G. 1967. Calcium exchange in cardiac muscle: A basic mechanism of drug action. Am. Heart J. 73: 379394.

70. Page, E., R. J. Goerke, and S. R. Storm. 1964. Cat heart muscle in vitro. IV. Inhibition of transport in quiescent muscles. J. Gen. Physiol. 47: 531-543.

71. Brown, E. B., Jr., and B. Goott. 1963. Intracellular hy- 
drogen ion changes and potassium movement. Am. J. Physiol. 204: 765-770.

72. Becker, L. D., R. Ferreira, and M. Thomas. 1975. Effect of propranolol and isoprenaline on regional left ventricular blood flow in experimental myocardial ischemia. Cardiovasc. Res. 9: 178-186.

73. Graham, T. P., Jr., J. Ross, Jr., J. W. Covell, E. H. Sonnenblick, and R. L. Clancy. 1967. Myocardial oxygen consumption in acute experimental cardiac depression. Circ. Res. 21: 123-138.

74. Reimer, K. A., M. M. Rasmussen, and R. B. Jennings. 1973. Reduction by propranolol of myocardial necrosis following temporary coronary artery occlusion in dogs. Circ. Res. 33: 353-363.

75. Sarnoff, S. J., J. P. Gilmore, R. H. McDonald, Jr., W. M. Daggett, M. L. Weisfeldt, and P. B. Mansfield. 1966. Relationship between myocardial $\mathrm{K}^{+}$balance, $\mathrm{O}_{2}$ consumption, and contractility. Am. J. Physiol. 211: 361-375.

76. Polimeni, P. I., and M. Vassalle. 1970. Potassium fluxes in Purkinje and ventricular muscle fibers during rest and activity. Am. J. Physiol. 218: 1381-1388.

77. Kupersmith, J., H. Shiang, R. S. Litwak, and M. V. Herman. 1976. Electrophysiological and antiarrhythmic effects of propranolol in canine acute myocardial ischemia. Circ. Res. 38: 302-307.

78. Wit, A. L., B. F. Hoffman, and M. R. Rosen. 1975. Electrophysiology and pharmacology of cardiac arrhythmias. IX. Cardiac electrophysiologic effects of beta adrenergic receptor stimulation and blockade. Part A. Am. Heart J. 90: 521-533.

79. Belardinelli, L. 1975. Reduction of acute myocardial ischemia with verapamil. Evaluation by epicardial mapping. Arq. Bras. Cardiol. 28: 599-607.

80. Shigenobu, K., J. A. Schneider, and N. Sperelakis. 1974 Verapamil blockade of slow $\mathrm{Na}^{+}$and $\mathrm{Ca}^{++}$responses in myocardial cells. J. Pharmacol. Exp. Ther. 190: 280-288.

81. Gettes, L. S., B. Surawicz, and J. C. Shiue. 1962. Effect of high $K$, low $K$, and quinidine on QRS duration and ventricular action potential. Am. J. Physiol. 203: 11351140.

82. Goerke, J., and E. Page. 1965. Cat heart muscle in vitro. VI. Potassium exchange in papillary muscles. $J$. Gen. Physiol. 48: 933-948.
83. Carmeliet, E. E., 1961. Chloride and Potassium Permeability in Cardiac Purkinje Fibers. Presses Académiques Européennes, Brussels. 152 pp.

84. Surawicz, B. 1967. Relationship between electrocardiogram and electrolytes. Am. Heart J. 73: 814-834.

85. Bellet, S., P. C. Gazes, and W. A. Steiger. 1950. The effect of potassium on the electrocardiogram in the normal dog and in dogs with myocardial infarction. Am. J. Med. Sci. 220: 237-246.

86. Sodi-Pallares, D., A. Bisteni, G. A. Medrano, A. De Micheli, J. Ponce De Leon, E. Calva, B. L. Fishleder, M. R. Testelli, and B. L. Miller. 1966. The polarizing treatment in cardiovascular conditions. Experimental basis and clinical applications. In Electrolytes and Cardiovascular Diseases. E. Bajusz, editor. S. Karger, New York. 2: 198-238.

87. Edeiken, J. 1954. Elevation of the RS-T segment, apparent or real, in the right precordial leads as a probable normal variant. Am. Heart J. 48: 331-339.

88. Goldman, M. J. 1953. RS-T segment elevation in mid- and left precordial leads as a normal variant. Am. Heart J. 46: 817-820.

89. Sjöstrand, T. 1950 . The relationship between the heart frequency and the S-T level of the electrocardiogram. Acta Med. Scand. 138: 201-210.

90. Hoffman, B. F. 1956. Temperature effects on cardiac transmembrane potentials. In The Physiology of Induced Hypothermia. N. A. S. N. R. C. Publ. 451: 302-324.

91. Toyoshima, H., M. Prinzmetal, M. Horiba, Y. Kobayashi, Y. Mizuno, R. Nakayama, and K. Yamada. 1965. The nature of normal and abnormal electrocardiograms. VIII. Relation of ST segment and $T$ wave changes to intracellular potentials. Arch. Intern. Med. 115: 4-16.

92. Helmholtz, H. von. 1853. Uber einige Gesetze der Vertheilung elektrischer Strome in korperlichen Leitern, mit Answendung auf die thier-elektrischen Versuche. Ann. Phys. Chem. 89: 211, 353.

93. Wilson, F. N., and R. H. Bayley. 1950. The electric field of an eccentric dipole in a homogeneous spherical conducting medium. Circulation 1: 84-92.

94. McFee, R., and F. D. Johnston. 1953. Electrocardiographic leads. I. Introduction. Circulation. 8: 554-568.

95. Boineau, J. P., and M. S. Spach. 1968. The relationship between the electrocardiogram and the electrical activity of the heart. J. Electrocardiol. (San Diego). 1: 117-124. 